\title{
Characterizing NWP Model Errors Using Doppler-Lidar Measurements of Recurrent Regional Diurnal Flows: Marine-Air Intrusions into the Columbia River Basin ${ }^{\mathscr{A}}$
}

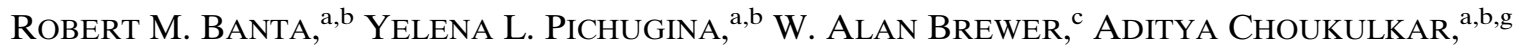 \\ KATHLEEN O. LANTZ, ${ }^{\mathrm{a}, \mathrm{b}}$ JOSEPH B. OlsON, ${ }^{\mathrm{a}, \mathrm{b}}$ JAYMES KENYON, ${ }^{\mathrm{a}, \mathrm{b}}$ HARINDRA J. S. FERNANDO, ${ }^{\mathrm{d}}$

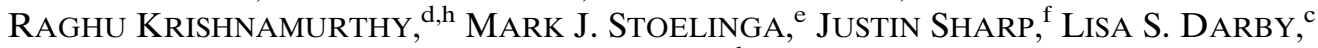 \\ DAVID D. TURNER, ${ }^{\mathrm{c}}$ SUNIL BAIDAR, ${ }^{\mathrm{a}, \mathrm{b}}$ AND SCOTT P. SANDBERG ${ }^{\mathrm{c}}$ \\ ${ }^{\text {a }}$ Cooperative Institute for Research in Environmental Sciences, Boulder, Colorado \\ ${ }^{\mathrm{b}}$ NOAA/Earth System Research Laboratory, Chemical Sciences Division, Global Monitoring Division, \\ and Global Systems Division, Boulder, Colorado \\ ${ }^{\mathrm{c}}$ NOAA/Earth System Research Laboratory, Chemical Sciences Division and \\ Physical Sciences Division, Boulder, Colorado \\ ${ }^{\mathrm{d}}$ Notre Dame University, South Bend, Indiana \\ ${ }^{\mathrm{e}}$ Vaisala, Inc., Seattle, Washington \\ ${ }^{\mathrm{f}}$ Sharply Focused, Portland, Oregon
}

(Manuscript received 12 June 2019, in final form 5 December 2019)

\begin{abstract}
Ground-based Doppler-lidar instrumentation provides atmospheric wind data at dramatically improved accuracies and spatial/temporal resolutions. These capabilities have provided new insights into atmospheric flow phenomena, but they also should have a strong role in NWP model improvement. Insight into the nature of model errors can be gained by studying recurrent atmospheric flows, here a regional summertime diurnal sea breeze and subsequent marine-air intrusion into the arid interior of Oregon-Washington, where these winds are an important wind-energy resource. These marine intrusions were sampled by three scanning Doppler lidars in the Columbia River basin as part of the Second Wind Forecast Improvement Project (WFIP2), using data from summer 2016. Lidar time-height cross sections of wind speed identified 8 days when the diurnal flow cycle (peak wind speeds at midnight, afternoon minima) was obvious and strong. The 8-day composite time-height cross sections of lidar wind speeds are used to validate those generated by the operational NCEP-HRRR model. HRRR simulated the diurnal wind cycle, but produced errors in the timing of onset and significant errors due to a premature nighttime demise of the intrusion flow, producing low-bias errors of $6 \mathrm{~m} \mathrm{~s}^{-1}$. Day-to-day and in the composite, whenever a marine intrusion occurred, HRRR made these same errors. The errors occurred under a range of gradient wind conditions indicating that they resulted from the misrepresentation of physical processes within a limited region around the measurement locations. Because of their generation within a limited geographical area, field measurement programs can be designed to find and address the sources of these NWP errors.
\end{abstract}

Supplemental information related to this paper is available at the Journals Online website: https://doi.org/10.1175/MWR-D-190188.s1.

\footnotetext{
${ }^{g}$ Current affiliation: Vibrant Clean Energy, LLC, Boulder, Colorado.

${ }^{\mathrm{h}}$ Current affiliation: Pacific Northwest National Laboratories, Richland, Washington.
}

Corresponding author: Robert M. Banta, robert.banta@noaa.gov

\section{Introduction}

Ground-based scanning Doppler lidars provide precise measurements of winds above Earth's surface at high spatial and temporal resolution. Once strictly a one-of-a-kind research tool (Post and Cupp 1990; Grund et al. 2001), advances in technology and commercialization have made lidars widely available over the past decades (Emeis et al. 2007; Pearson et al. 2009). Multiple Doppler lidars can now be deployed in arrays over an area to understand the horizontal structure of atmospheric flows and the spatial variability of wind-profile properties (Banta et al. 2013; Barthelmie et al. 2014; 
Fernando et al. 2015, 2019; Pichugina et al. 2019). Scanning Doppler lidars have demonstrated the ability to reveal the detailed structure of atmospheric phenomena, such as low-level jets (LLJs; e.g., Banta et al. 2002; Banta 2008; Pichugina and Banta 2010; Pichugina et al. 2017a,b; Bonin et al. 2015; Carroll et al. 2019; Smith et al. 2019), density currents (Sun et al. 2002; Darby et al. 2002a; Gohm et al. 2010; Toms et al. 2017), KelvinHelmholtz-type instabilities (Newsom and Banta 2003), mountain waves (Clark et al. 1994), sea breezes (Banta et al. 1993, 2005; Darby et al. 2002b; Chen et al. 2019), and many others.

These measurement capabilities should also be of great benefit for numerical weather prediction (NWP) improvement. Obviously, precise measurements through the lower troposphere are needed for validation against model predictions and quantification of the measurementmodel differences (errors) (e.g., Darby et al. 2002b, 2007; Darby and Poulos 2006; Pichugina et al. 2017b, 2019; Djalalova et al. 2016; Banta et al. 2018). Accurate measurements are essential to evaluate model responses to changes in model configuration, such as model-physics routines, to see whether the new schemes improve skill or not (e.g., Olson et al. 2019b; FernándezGonzález et al. 2018). But another significant issue is whether field campaigns that include these new instrument arrays can give deeper insight into the nature of model errors. Such insight could provide important clues as to where models most need improvement.

Model validation often involves comparing measurements at a given location to model values for the same location. A question is, are the errors detected in this way mostly imported from upstream, or generated more locally? If imported, they represent an amalgamation of errors along the modeled trajectories of air reaching the site, and it is a significant - perhaps insurmountable — challenge to disentangle the sources of the errors. But if conditions exist where the detected errors are mostly generated locally within a limited region around the measurement site, then measurement campaigns can be designed for model evaluation by validating the model, characterizing the model errors, then diagnosing the sources of the errors over this region to gain insight into how to improve the models. Error types detected in this way would also be characteristic of more general model shortcomings over continental or even global scales, even though they were found within a limited domain.

Examples where local forcing dominates the evolution of low-level winds include recurrent wind systems driven by the diurnal heating-cooling cycle at the surface. Such flows provide an opportunity to evaluate the skill of NWP models in properly simulating the flows themselves, as well as the wide range of physical processes and interactions producing them. These processes include surface heating, the atmospheric boundary layer $(\mathrm{ABL})$ response, the resulting vertical and horizontal transports, and many others, processes that are now parameterized at small scales or even resolved in continental-domain forecast models (e.g., Benjamin et al. 2016; Banta et al. 2018). Here we present an example of how accurate measurements of recurrent flows can reveal the nature of model errors.

The recurrent flow system investigated is a diurnal intrusion of moist air into the arid interior of Oregon and Washington. On many summertime days in the Columbia River basin of this region, westerly winds have a diurnal cycle, whereby wind speeds reach peak values near local midnight and minima around noon. These winds are an inland penetration of the sea breeze initiated at the coast and propagating eastward through passes, saddles, and other gaps in the Cascade Mountain Range, the major barrier impeding the spread of Pacific marine air into the basins to the east (see model animations in the online supplemental material). The diurnal winds are driven by strong daytime heating-surface peak temperatures routinely exceeding $30^{\circ} \mathrm{C}$ - to the east of the Cascades in summer. Westerly gap winds triggered by marine intrusions constitute a significant warm-season source of wind energy (WE) for this region, where Oregon-Washington WE comprises more than $6 \mathrm{GW}$ of installed generation capacity $^{1}$ (American Wind Energy Association 2018, p. 33). Much of this electricity is transmitted to coastal urban centers in Oregon and Washington, and to the south in California. Because of the importance of these winds to WE operations, it is important for that industry to be able to characterize, understand, model numerically, and forecast their occurrence to high precision (Ahlstrom et al. 2013).

The regional sea breezes through the Columbia Gorge, with their intrusions of strong westerly winds, are resolved by NWP forecast models of sufficiently fine horizontal resolution. In the following, we show how lidar wind-profile measurements of this regional wind system provide an opportune dataset to characterize model errors. For the cases presented here, similar model errors occurred under a range of external conditions, and thus represented a type of model error generated within a $100-$ to $300-\mathrm{km}$ purlieu or neighborhood of the measurement locations. These errors would result from the model's inability to accurately simulate loweratmospheric processes over that area.

\footnotetext{
${ }^{1}$ More detailed information is available at: https://eerscmap.usgs. gov/uswtdb/viewer.
} 
The summertime intrusions studied here were well sampled by three scanning Doppler lidars during the Columbia basin field campaign. Data from these lidars have already been used to characterize the differences in wind properties among the three sites over seasonal and annual time periods (Pichugina et al. 2019). That study also used the lidar dataset to evaluate the skill of the NOAA/NCEP operational High-Resolution Rapid Refresh (HRRR) forecast model in simulating these properties and their site-to-site differences over the same averaging periods (Pichugina et al. 2019). For the validations in the present study, we again use the HRRR-model versions that were running operationally at NCEP during summer 2016. Future studies will investigate experimental versions of HRRR being run at ESRL to test alternative physics, horizontal resolution, and other new model packages (Olson et al. 2019b).

The lidar measurements were taken in the Columbia basin as part of a larger-scale, 18-month field campaign, which was motivated by the need to improve the quality of wind information available to WE, including more accurate climatological wind data in the turbine rotor layer and more accurate forecasts of winds at the same heights. Thus, we will generally use heights and variables of interest to WE as examples.

To evaluate the skill of HRRR in simulating marineintrusion events and to explore the nature of significant model errors in these simulations, we must first characterize the diurnal evolution of the vertical flow structure of the marine-intrusion life cycle over the Columbia River basin, so we can be clear about what HRRR is trying to model. The nature and vertical structure of Pacific moist-air penetrations eastward past the Cascades have not been well documented in this region, so we use the Doppler-lidar profile data and other available measurements to describe and understand these flows. We evaluate the ability of the model to replicate the observed typical moist, westerly flow intrusion by compositing both the lidar data at each site and the corresponding model-output values, as timeheight cross sections, time series, or wind profiles, and calculating model-error statistics. Results presented here depended critically on having data from a field program with high-quality measurements of vertical profiles over a well-designed, nested array (Banta et al. 2013; Wilczak et al. 2019). Based on results here, we provide recommendations for future projects aimed at understanding phenomena and improving model skill.

\section{Data, methods, and HRRR model description}

The topography of the study region is shown in Fig. 1a. To the west, two north-south ranges of mountains, the
Coastal and Cascade Ranges, and an intervening valley (in Oregon, the Willamette Valley extending south from Portland) separate the interior Columbia basin from the Pacific Ocean. As noted, the second, easternmost, Cascade Range presents the major barrier to the eastward spread of moist marine air from the Pacific Ocean into the basin area, and the Columbia River Gorge cuts through this range from east to west. The Columbia basin has two regions, a "wind-energy corridor" described here, which extends from the Columbia Gorge opening west of The Dalles eastward past Boardman. To the north, and separated from the wind-energy corridor by a ridge, is the Pasco subbasin (Whiteman et al. 2001), a region characterized by Staley (1959) as a roughly "circular basin," including cities such as Ellensburg (ELN see Fig. 1a), Moses Lake, and Pasco, Washington. Near-surface winds in the wind-energy corridor, including turbine rotor-layer winds, have a bidirectional distribution (Fig. 2) whereby the winds are either from a narrow range of northwesterly, westerly, or southwesterly directions or from a narrow range of easterly component directions, but seldom from any other direction, indicating strong topographic influence (Pichugina et al. 2019). Sharp and Mass $(2002,2004)$ and Neiman et al. (2019) studied the wind flow through the narrow gorge and point out that the gap winds there are strongly controlled by the surface pressure gradient across the Cascade barrier. Over the Pasco subbasin region to the north, Staley (1959) found that diurnal hodographs of the surface winds at a few but not all of the stations during the July-August period of his study show similar topographic-channeling effects, and Brewer and Mass (2014) also found that summertime surface winds at many locations in Oregon and Washington blow from a narrow range of directions.

Lidar sites in this basin were at Wasco, Arlington, and Boardman, Oregon. Figure 1b shows an enlargement of the lidar study area with the locations of the lidars, showing how the lidar sites straddled several large wind farms (clustered wind turbines, each turbine represented by an orange symbol) and the elevation of each site (Wasco at $452 \mathrm{~m} \mathrm{MSL}$, Arlington at $262 \mathrm{~m}$, and Boardman at $110 \mathrm{~m}$ MSL). The present study concerns the diurnal penetration of moist air from west of the Cascades into this region, a distance of $200-300 \mathrm{~km}$ inland from the ocean.

\section{a. Background: The regional sea breeze}

Sea breezes have been intensively investigated for more than a century (e.g., Defant 1951; Miller et al. 2003). They have been found to penetrate well inland in several investigations; for example, Simpson (1994) described studies where sea-breeze fronts were traced 

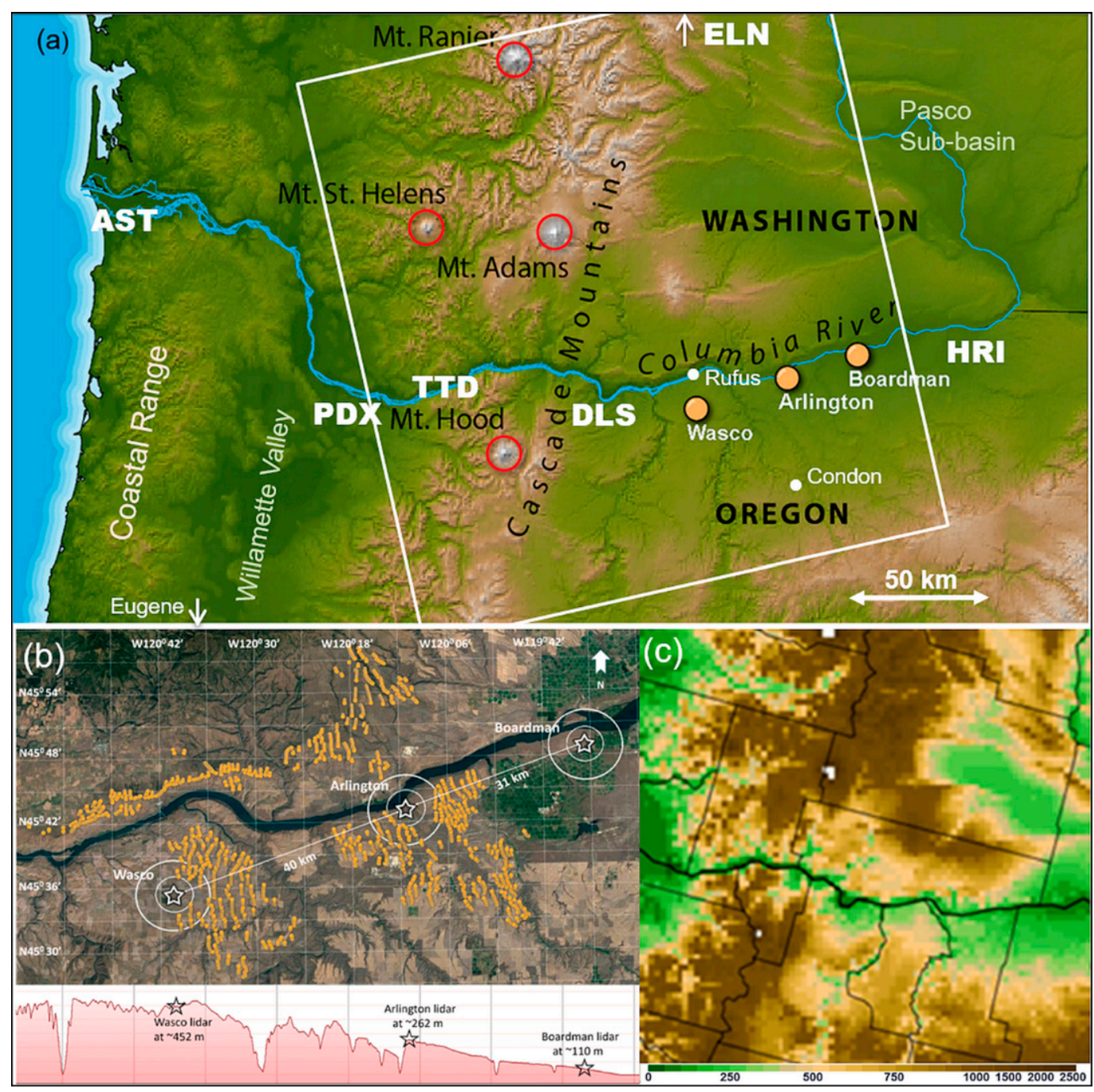

FIG. 1. (a) Map of the study area in Columbia River valley, where locations of scanning Doppler lidars are denoted by yellow circles [adapted from Pichugina et al. (2019)]. NWS sites shown in white capital letters: AST, Astoria; PDX, Portland airport; TTD, Troutdale; ELN, Ellensburg; DLS, the Dalles; and HRI, Hermiston. (b) Enlargement of study area, top panel showing a Google Earth map of the Eastern Gorge portion of study area, with the locations of Doppler lidars at Wasco, Arlington, and Boardman, OR. Surrounding wind farms are indicated by clusters of orange dots (each dot represents a turbine). White line indicates a WSW-ENE transect of the study region, approximately along the prevalent wind directions found by Pichugina et al. (2019). Bottom panel of (b) shows terrain elevation along this line, where lidar locations are indicated by black stars. Adapted from Pichugina et al. (2019). (c) Terrain for the white box area in (a), as represented in the 3-km HRRR; color scale at bottom in $\mathrm{m}$ MSL.

several tens of $\mathrm{km}$ onshore. In their reviews, Atkinson (1981), Pielke (1984), Miller et al. (2003), and Crosman and Horel (2010) list studies where the sea breeze pushed in $100-300 \mathrm{~km}$ from the shore; and $\mathrm{Hu}$ and Xue (2016) detected sea-breeze air near Dallas, Texas, $400 \mathrm{~km}$ from the Gulf of Mexico coastline, where the flow originated, aided by a strong southerly nocturnal LLJ.

Density-current (or cold-frontal) structure has been noted in many sea-breeze studies, especially near the coastline when the sea breeze forms in offshore ambient flow (e.g., Holland and McBride 1989; Gilliam et al. 2004). Even in large-scale onshore flow conditions as encountered in the present study, however, Reible et al. (1993) and Simpson (1994) have argued that, as the sea-breeze air mass propagates inland during the day, the leading edge can encounter surface heating, which warms, modifies, and retards its advance with respect to the cooler air behind it, leading to frontogenesis, or a sharpening of the front at its leading edge. Marine air 

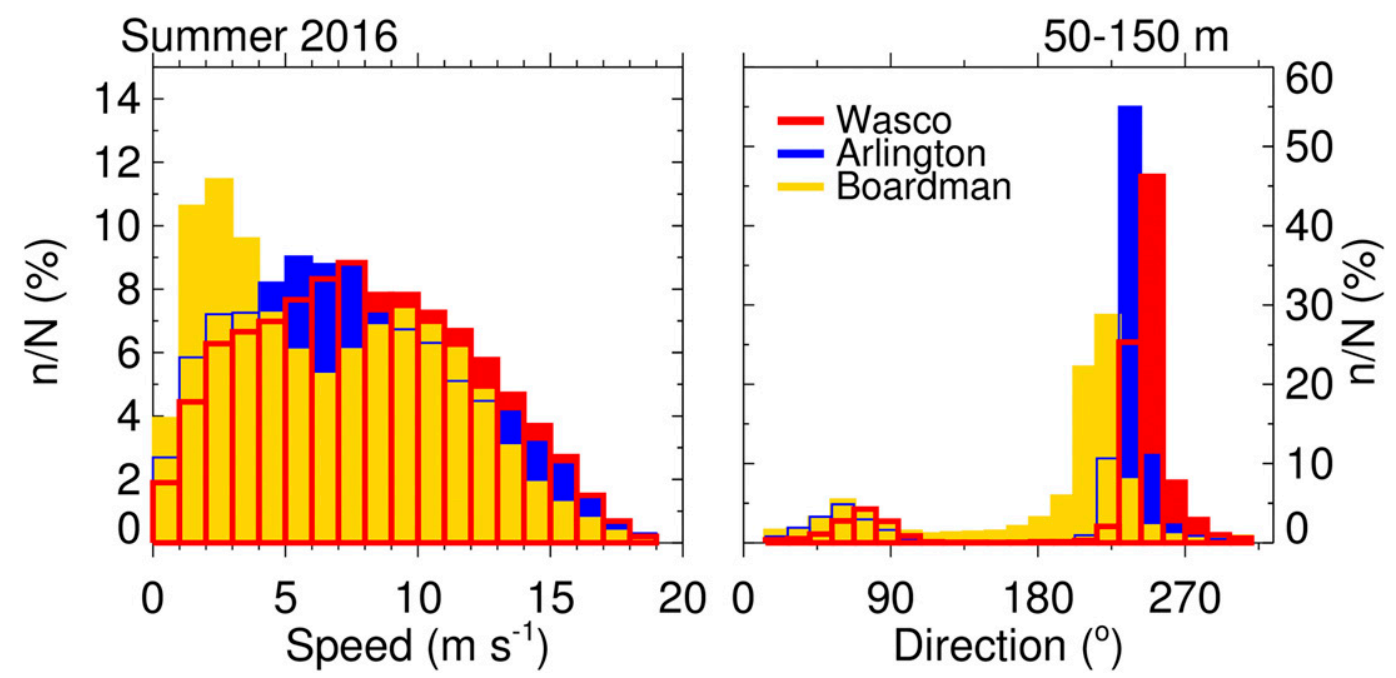

FIG. 2. Histograms of wind (left) speed and (right) direction averaged over the 50-150-m AGL vertical layer at the three Doppler sites for the June, July, and August period [reproduced from Pichugina et al. (2019)].

having a diffuse boundary near the coast may thus acquire density-current structure as it pushes inland (Mayor 2011).

Along the Pacific coast of the United States, inland penetrations of marine air have been linked to a combination of large-scale conditions-a persistent offshore ridge in summer-and more local, sea-breeze dynamics, including hot afternoon maximum surface temperatures well inland, often greater than $35^{\circ} \mathrm{C}$. Several studies of these flows have observed frontal structure at the leading edge of the marine air, consisting of a propagating wind-shift line and a zone of horizontal temperature gradient. Often these zones separate as the front moves inland, the wind shift line preceding the temperature gradient inland (Fosberg and Schroeder 1966; Olsson et al. 1973). These studies address the advance of the cool, moist, marine air past the coastal ranges of California (Fosberg and Schroeder 1966; Schroeder et al. 1967; Zaremba and Carroll 1999; Darby et al. 2002b; Wang and Ullrich 2018), Oregon (Olsson et al. 1973; Johnson and O'Brien 1973), and Washington (Mass et al. 1986). But they do not discuss the diurnal flows of air through the second ranges, the Cascades in Oregon and Washington, and the Sierra Nevada in California (Zhong et al. 2008), and into the U.S. Great Basin regions as described in the present paper.

Three studies have described averaged July-August winds east of the Cascades based mostly on surfacestation data. Doran and Zhong (1994), Brewer and Mass (2014), and the previously mentioned study by Staley (1959) all found accelerations of westerly component winds to $8-10 \mathrm{~m} \mathrm{~s}^{-1}$ during late afternoon at sites in the western portions of the Columbia basin. The features were seen in the data averaged by hour of day, indicating a diurnal pattern, and they moved from west to east through the basin. These strong westerlies often lasted $6 \mathrm{~h}$ or more but decreased in speed after the first hour. Pibal measurements in two of the studies showed that they were at least $700 \mathrm{~m}$ deep. One of the stations where this feature was observed was Ellensburg (ELN) in the western Pasco subbasin. There, northwesterly flow descends from the 919-m Snoqualmie Pass, in contrast to our study area, where the passage through the Columbia Gorge is near sea level, and what elevation there is, tilts downward toward the west. Looking at the individual days in their sample, Doran and Zhong (1994) noted differences in the evolution of these events from case to case, and identified three categories: "typical" events, when "the wind speed rose steadily and quickly around 1800 or 1900 PST; 'early onset' events, in which the winds were already blowing strongly by 1800 PST [0200 UTC]," and occurrences when the accelerations were later in the evening. In the early onset cases, the westerly or northwesterly winds were blowing over the basin area during daylight hours well before sunset.

Staley (1959), having previously studied the sea breezes in Washington west of the Cascades (Staley 1957), concluded, "these events may be interpreted as an inland progression of a massive circulation associated with differential heating between the Columbia Basin, and Puget Sound and the Pacific Ocean to the west." Although the forcing is complex and many mechanisms operate through the course of these flows, he found, "the inland progression of a sea-breeze circulation [to be] a dominant effect." Although Doran and Zhong (1994) 
TABLE 1. System parameters for Doppler lidars.

\begin{tabular}{lcc}
\hline \hline \multicolumn{1}{c}{ Lidar parameters } & $\begin{array}{c}\text { WindCube 200S } \\
(100-\mathrm{m} \text { gate })\end{array}$ & $\begin{array}{c}\text { Halo Streamliner } \\
\text { XR (30-m gate) }\end{array}$ \\
\hline Wavelength $(\mu \mathrm{m})$ & 1.54 & 1.5 \\
Pulse energy $(\mathrm{mJ})$ & 0.1 & 0.08 \\
Pulse duration $(\mathrm{ns})$ & 400 & 350 \\
Pulse repetition & 10000 & 10000 \\
$\quad$ frequency $(\mathrm{Hz})$ & & \\
Sampling frequency $(\mathrm{MHz})$ & 250 & 50 \\
Accumulation time $(\mathrm{s})$ & $0.5 / 1$ & $0.5 / 1$ \\
Range resolution $(\mathrm{m})$ & 100 & 48 \\
Minimum range $(\mathrm{km})$ & 0.2 & $3-5$ \\
Typical max range $(\mathrm{km})$ & $5-7$ & \\
\hline
\end{tabular}

called their diurnal phenomena "drainage flows," they cautioned at several points that, "they do not conform to the normal features of winds associated with katabatic forcing." Those nonconforming features-afternoon onset, deep layer of flow, decreasing speeds through nighttime hours-are consistent with Staley's regional sea-breeze interpretation.

Weather forecast models such as the 3-km HRRR are capable of resolving these regional flows and their driving physics, but detailed validations of the vertical structure of these flows have not been reported. In the present study, we perform such validations using lidar.

\section{b. Instrumentation}

The scanning lidars used to study these flows in the Columbia basin were two Leosphere 200S lidars deployed by NOAA/ESRL (Wasco, Arlington) and a Halo Photonics Streamline system (Pearson et al. 2009) deployed by Notre Dame University (Boardman). Specifications of the lidars used during the summer of 2016 are listed in Table 1. The lidars performed coordinated scanning sequences of conical scans, elevation scans, and vertical stares every $15 \mathrm{~min}$ as listed in Table 2.

Data from these scan sequences were processed into 15 -min vertical profiles of the wind vector as described by Pichugina et al. (2019). Our lidar mean-wind profile calculation consists of using the velocity-azimuth display (VAD) procedure (Lhermitte and Atlas 1961; Browning and Wexler 1968), modified to include all scans (Banta et al. 2002, 2015, 2018; Pichugina et al. 2019) taken within the 12 -min averaging period that excludes the vertically pointing data from the last $3 \mathrm{~min}$ (Table 2). Data were binned into 10-m intervals (up to $200 \mathrm{~m}$ ) by height above ground level (AGL). For each of these periods and for each vertical bin, all wind data from all scans having data in that bin are combined into one large sample of $\left(\theta, u_{\mathrm{rh}}\right)$ points on which the
TABLE 2. Scan sequences continuously performed by lidars every 15-min at the three sites during summer 2016.

\begin{tabular}{lccc}
\hline \hline & Elevation $\left(^{\circ}\right)$ & Azimuth $\left(^{\circ}\right)$ & $\begin{array}{c}\text { Duration } \\
(\mathrm{min})\end{array}$ \\
\hline Scan type & \multicolumn{3}{c}{ Wasco } \\
Conical (PPI) & $2.75,4,6,15,45$ & $0-360$ scanning & 8.5 \\
Elevation (RHI) & $0-30$ scanning & $0,90,180,270$ & 3.5 \\
Vertical stare & 90 & - & 5,3 \\
& \multicolumn{4}{c}{ Arlington } \\
Conical (PPI) & $1.75,3,6,15,45$ & $0-360$ scanning & 8.5 \\
Elevation (RHI) & $0-30$ scanning & $0,90,180,270$ & 3.5 \\
Vertical stare & 90 & - & 5,3 \\
& \multicolumn{4}{c}{ Boardman } \\
Conical (PPI) & $1.75,3,6,15,45$ & $0-360$ scanning & 6.5 \\
Elevation (RHI) & $0-30$ scanning & $0,90,180,270$ & 8.5 \\
Vertical stare & 90 & - & 3.5 \\
\hline
\end{tabular}

VAD calculation is then performed, where $\theta$ is the beam azimuth and $u_{\mathrm{rh}}$ is the horizontal projection of the radial or line-of-sight wind component $u_{r}$ measured by the lidar. Thus, the data that go into each mean-wind profile are from a mound of data points taken over a 12-min period, divided into layers or bins in the vertical.

Each bin is therefore a horizontal disk of data, whose diameter is determined by the lowest-elevation (widest) conical scan that intersects the layer; this diameter could be $10 \mathrm{~km}$ or more at low elevations. All of these vertically stacked bins contain data distributed over the disk from the other $360^{\circ}$ conical scans and the four elevation scans, over the 12-min sampling period. The data are subjected to quality control (QA) procedures that eliminate outliers at each level due to insufficient signal strength, spurious hard-target returns, sharp turbulent bursts, significant small-scale terrain effects, and other strong $u_{\mathrm{rh}}$ anomalies that are unrelated to the mean flow, as described by Pichugina et al. (2019). In summary, the result of this procedure is that in each layer in the vertical, winds are averaged over quality controlled data that are spread over a sampling disk, which could be $10 \mathrm{~km}$ across, from scans that span a $12-$ min period. This averaging provides a profile smoothed in space and time, similar in many respects to the smoothing inherent in NWP model fields (Skamarock 2004).

Although analyzed wind data from the lowestelevation scans were available at fine vertical intervals of less than $1 \mathrm{~m}$ near the ground (e.g., Banta et al. 2015), they were averaged over larger intervals of $\sim 10 \mathrm{~m}$ in the lowest $200 \mathrm{~m}$ for purposes of this study, to compare with HRRR model output. The accuracy of contemporary Doppler-lidar mean-wind profile measurements has been assessed to be $<0.1 \mathrm{~m} \mathrm{~s}^{-1}$ (Banta et al. 2013; Klaas et al. 2015; and, using the WFIP2 dataset, Pichugina et al. 2019). The profiles are available every $15 \mathrm{~min}$, so 
we will refer to them as 15 -min profiles even though the scans from which they were calculated only occupied the first $12 \mathrm{~min}$ of each interval.

The instrument deployment for this project was part of the WFIP2 campaign. Descriptions of the experiment are given in overview articles (Shaw et al. 2019; Wilczak et al. 2019; Olson et al. 2019b). For this paper, in addition to the lidars we used a limited set of instrumentation, including NWS airport-site observations and rawinsonde data that would be available to operational forecasters. To document the primary diurnal solar forcing for these flows, its horizontal variability, and the ability of HRRR to reproduce it, sites measuring surface radiation were located at three Oregon locations: Condon, Wasco, and Rufus. Data from a similar fourth site at Eugene, Oregon, were also available, to provide an additional perspective on radiation outside of the basin. A SURFRAD station (Augustine et al. 2000) was located at Wasco for measuring the radiation budget [downwelling and upwelling shortwave (SW) and longwave (LW) radiation]. Portable radiometer systems designed to measure downwelling SW (including direct and diffuse) and LW radiation were deployed to Rufus and Condon. All four stations had the requisite observations for the RadFlux analysis for deriving additional clear-sky radiation variables and cloud products (Long and Ackerman 2000; Long et al. 2006). We note that the only component of the total radiation saved for the HRRR output was the incoming SW, so we show only SW measurements here.

The diurnal flows of interest were detected at Wasco at or just before 0000 UTC, then often lasted for more than $8 \mathrm{~h}$. Although it is customary to show diurnal time series and time-height cross sections in local standard time to facilitate understanding of flows with respect to day and night, in this analysis we will use UTC for these plots, because on most days the intrusion flow can be shown in its entirety. If shown in local time [Pacific standard time (PST), which is $8 \mathrm{~h}$ behind UTC], the flows of interest would be split in two. An exception to this will be the presentation of model comparisons of SW radiation plots, which will be shown in PST so that the daytime solar curve is not divided in two.

\section{c. Operational HRRR model description}

The HRRR forecast model used for this study was HRRR-v1 and v2 (Benjamin et al. 2016) as run at NCEP during the experiment. The HRRR is an hourly updated, convection-allowing numerical-forecast model having $3-\mathrm{km}$ horizontal grid spacing of unsmoothed terrain, running on a domain that encompasses the continental United States (see maps in Olson et al. 2019b). An operational adaptation of the Weather Research and
Forecasting (WRF) Model, it is used by many windindustry forecasting vendors in formulating their predictions of turbine rotor-layer winds (Olson et al. 2019b). The operational HRRR model evaluated here was upgraded at NCEP to HRRR v2 on 23 August 2016. With this upgrade, improvements to data-assimilation and physics components were implemented (Benjamin et al. 2016, e.g., their Table 8), to include changes in the handling of mixing length and soil moisture, and a parameterization of subgrid-scale clouds.

Benjamin et al. (2016) describe many of the components and novel features of the 13-km Rapid Refresh (RAP), the model in which the HRRR is nested, including its initialization scheme; much of this description is pertinent to the HRRR as well. Both models employ MYNN surface-layer and PBL schemes (PBL level 2.5; Nakanishi and Niino 2009), the RRTMG shortwave (SW) and longwave (LW) radiation schemes (Iacono et al. 2008), and other model physics routines as described in Benjamin et al. (2016) and Olson et al. (2019a,b). An exception where RAP and HRRR are different is that the RAP initialization employs a digitalfilter initialization (DFI; Peckham et al. 2016) to improve initial-condition balance and suppress spurious gravity wave generation, which would contaminate the numerical solution and generate errors. The current HRRR does not employ this DFI after data assimilation. It was found during experimental model runs based on the WFIP-2 dataset that using DFI in HRRR suppressed several types of model error, including some described in this paper, thus improving model skill. As a result, it is likely that a future operational version of HRRR will contain a component to the initialization similar to DFI.

Model wind values were interpolated to the lidarsite locations using bilinear interpolation, and to the lidar vertical levels. Because of the large volume of information generated by HRRR, model output was saved only every hour, so the 15-min lidar data had to be averaged. For this study the lidar data were averaged for the 15-min profiles immediately before and after the top of the hour.

\section{Results-Measurements}

During summer 2016 a distinct diurnal pattern was often evident in the wind power generated over the Bonneville Power Administration (BPA) region, for example Fig. 3 shows four consecutive days in August when the aggregated wind-generated power peaked at midnight local time and bottomed at noon. This behavior implies a diurnal cycle of winds at least through the wind-turbine rotor layer, roughly 50-150 m AGL. 


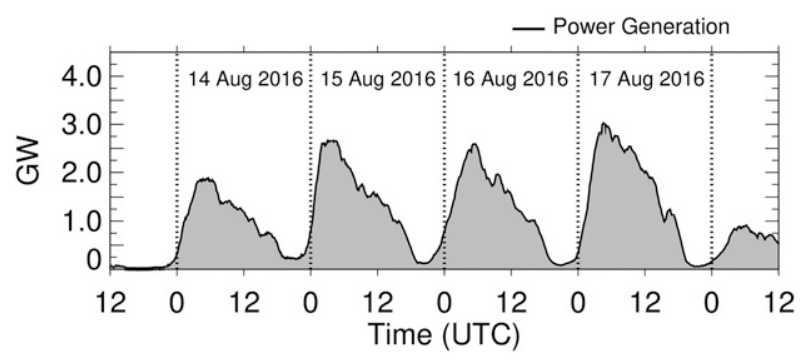

FIG. 3. Time series of total BPA wind power generated for a $120-\mathrm{h}$ (5 day) period in August 2016.

\section{a. The marine intrusion: Individual days}

Time-height cross sections up to $1 \mathrm{~km}$ AGL of the wind patterns that produced the diurnal power modulation in Fig. 3 are shown in Fig. 4 for the last two of the four days. The data displayed use the 15-min lidarmeasured wind speed profiles taken on 16-17 August for each of the three sites. All show a surface-based layer of strong winds exceeding $12 \mathrm{~m} \mathrm{~s}^{-1}$ at night. The flow rapidly accelerated in late afternoon through a layer more than $400 \mathrm{~m}$ deep, appearing first, and strongest, at the westernmost site Wasco at $\sim 0000$ UTC, then Arlington at $\sim 0200 \mathrm{UTC}$, and then the easternmost site,
Boardman, at $\sim 0400$ UTC, for a mean propagation speed of $5 \mathrm{~m} \mathrm{~s}^{-1}$ over the $71 \mathrm{~km}$ distance between Wasco and Boardman. Pichugina et al. (2019) and Wilczak et al. (2019) show lidar time-height cross sections for days in June 2016 when this pattern was also apparent.

The strength and depth of the lidar-observed westerly accelerations and their day-to-day repeatability show that they are a vigorous response to strong diurnal forcing. They represent a manifestation of the deep sea breeze described along the California coast by Banta (1995) and Darby et al. (2002b). The arrival of this westerly flow disturbance fully formed at Wasco during the afternoon, sometimes as early as 2300 UTC (1500 PST) resembles Doran and Zhong's (1994) early onset cases farther north. It rules out any surface-cooling explanations, such as drainage effects, as the dominant forcing of these flows. For these westerly accelerations, we agree with Staley's (1959) assessment, that regionalscale sea-breeze forcing is the most probable explanation, especially in the WFIP2 area to the east of the Columbia Gorge, where the flow does not have to go over a 900-m mountain pass.

The depth, maximum strength, and duration of the strong westerly flow layer varied from site to site and
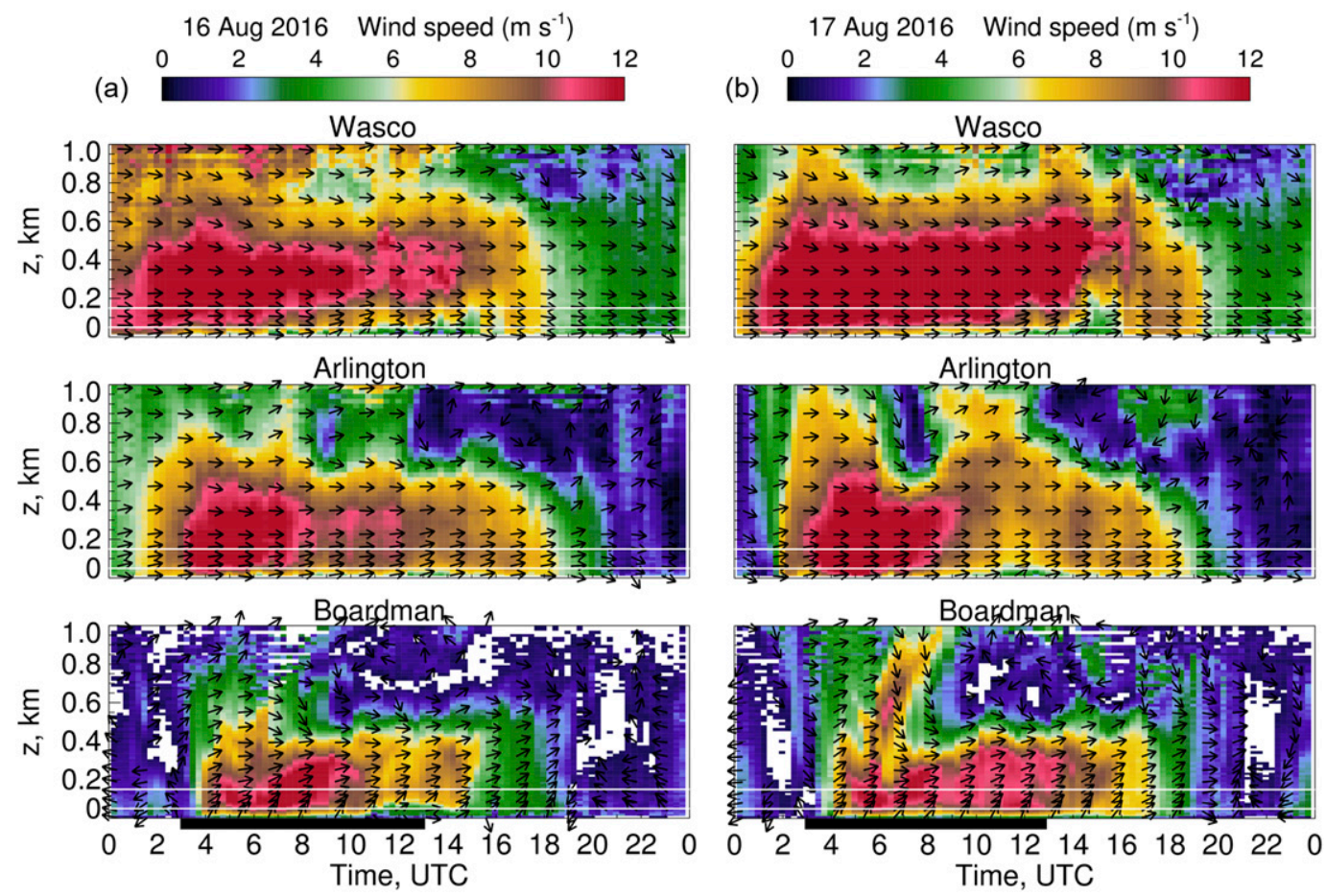

FIG. 4. Time-height cross sections of wind speed ( $\mathrm{m} \mathrm{s}^{-1}$, color bar at top) measured by Doppler lidars at (from top to bottom) Wasco, Arlington, and Boardman for: (a) 16 Aug and (b) 17 Aug 2016. Black lines along bottom axes indicate nighttime hours. Black arrows show wind direction: right-pointing for westerly and downwardpointing for northerly. White areas within the Boardman cross sections represent missing data, which were ignored in calculating composited data. Horizontal white parallel lines show turbine rotor layer. 
from day to day. The deep, often abrupt leading edge of the flow during onset bears some resemblance to the vertical kinematic structure of a front or density current, as noted in previous sea-breeze studies and seen in other lidar studies (e.g., Gohm et al. 2010; Darby et al. 2002b; Intrieri et al. 1990; Nakane and Sasano 1986; Banta et al. 2005; Mayor 2011). Flow stronger than $8 \mathrm{~m} \mathrm{~s}^{-1}$ persisted through the layer until after 1700 UTC the next morning at Wasco and Arlington, and 1500 UTC at Boardman. A sunrise or presunrise lull in wind speeds below $200 \mathrm{~m}$ is seen between 1100 and 1500 UTC, especially evident at Wasco, most likely due to the buildup of a cold-air, light-wind inversion layer overnight. Time-height cross sections of temperature from a microwave radiometer at the Wasco site (example shown in the appendix) indicate the buildup of such a low-level inversion layer each night of this study. Minimum wind speeds, found midday to afternoon through the kilometer depth of the display, appeared generally well mixed.

We perused each day of data in June, July, and August 2016 to identify all definitive sea-breeze/marine-intrusion occurrences, as just described. For this purpose, we used Doppler-lidar time-height and time series data as the standard reference dataset, and supplementary data from other sources. We looked for a strong, late-afternoon upsurge of westerly flow propagating west to east that mixed out by the following late morning to early afternoon at each site. Two criteria were used: 1 ) the $100-\mathrm{m}$ AGL wind at each site exceeded $10 \mathrm{~m} \mathrm{~s}^{-1}$ for at least $6 \mathrm{~h}$ at Wasco, $3 \mathrm{~h}$ at Arlington, and $1 \mathrm{~h}$ at Boardman, and 2 ) the previous afternoon minimum 100-m wind speed between 1800 and 0300 UTC at Arlington was no greater than $3 \mathrm{~m} \mathrm{~s}^{-1}$. An accompanying increase in water vapor and a drop in temperature were present on many days.

Figure 5a, for example, shows the temperature and dewpoint for Astoria, Oregon, at the coast, where the flow was onshore, and for Hermiston, well inland in the Columbia basin (cf. Fig. 1a). The dewpoint at the coast had a steady value all day, whereas the value at the inland site increased from dry afternoon values to a value nearly equal to that at the coast after 0600 UTC. The intrusion air mass was thus moister than the prefrontal afternoon air in the basin, and often cooler. Combined with the persistent westerly component flow, this indicates that the intrusion air originated west of the Cascade barrier, where the major source of moist air is the Pacific Ocean. Although evaporation from rivers, lakes, irrigation, and moist soil can contribute, and although the air mass is likely to be modified over the 200$300 \mathrm{~km}$ transit into the basin, we will refer to this air as marine air; peak moisture values after the passage of the wind acceleration often reach the values seen at the coast, as seen in Fig. 5a.
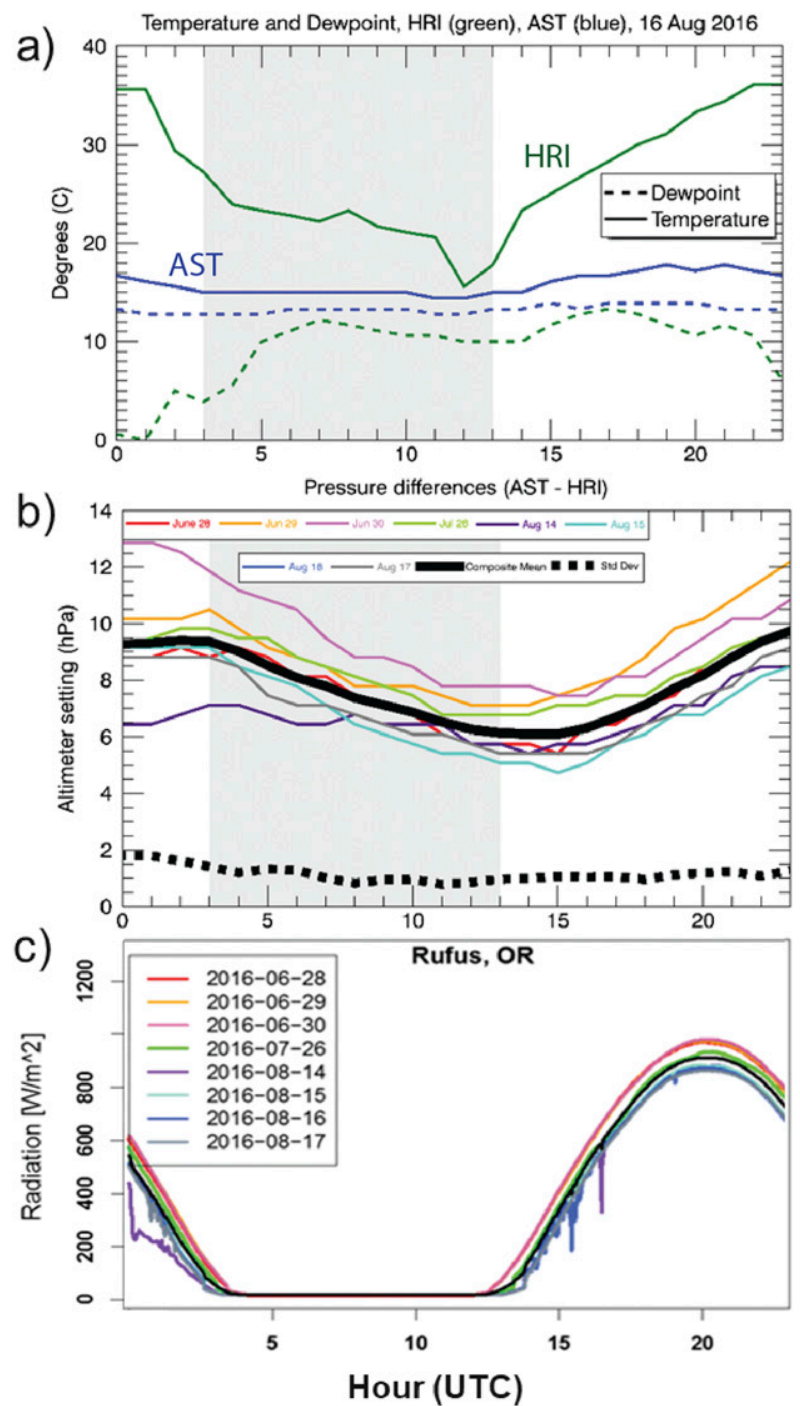

FIG. 5. (a) Surface temperature (solid) and dewpoint (dashed) measured at NWS stations at coastal Astoria (AST, blue) and inland Hermiston (HRI, green) plotted against hour of day (UTC). Nighttime hours shaded. (b) Differences in altimeter setting (hPa) between reported values at Astoria and Hermiston for each of the eight marine-intrusion days (color coded) and for the composite mean (thick black line). (c) Shortwave solar radiation at the surface $\left(\mathrm{W} \mathrm{m}^{-2}\right)$, measured at Rufus, plotted against hour of day (UTC). Colored curves are each for the day indicated, and black is the composite mean value.

Many days had these characteristics for part of the day, but the cycle was interrupted by weak largerscale fronts, troughs, lines of moist convection, or other disturbances; these days were excluded from our sample of pure, full-cycle, marine-intrusion days. The result was nine days, of which one (30 August) turned out to be cloudy much of the day, so it was rejected as nonstandard. The final dataset of marine-intrusion cases thus consists of eight days from summer 2016. Data from 
TABLE 3. Dates used in composite analyses; sunrise/sunset at Hermiston, OR, from NWS station data, and 700-mb rawinsonde data for Salem, OR (SLE), and Spokane, WA $(\mathrm{OTX}),\left(1 \mathrm{kt} \approx 0.5144 \mathrm{~m} \mathrm{~s}^{-1}\right)$.

\begin{tabular}{|c|c|c|c|c|c|c|c|}
\hline Date (2016) & Sunrise PST (UTC) & Sunset PST (UTC) & UTC & $\begin{array}{l}\text { SLE 700-mb } \\
\text { direction }\end{array}$ & $\begin{array}{l}\text { SLE 700-mb } \\
\text { speed (kt) }\end{array}$ & $\begin{array}{l}\text { OTX 700-mb } \\
\text { direction }\end{array}$ & $\begin{array}{c}\text { OTX 700-mb } \\
\text { speed (kt) }\end{array}$ \\
\hline \multirow[t]{2}{*}{28 Jun } & $0410(1210)$ & 1951 (0351) & 0000 & 200 & 15 & 215 & 10 \\
\hline & & & 1200 & 230 & 7 & 250 & 12 \\
\hline \multirow[t]{2}{*}{29 Jun } & 0411 (1211) & 1951 (0351) & 0000 & 210 & 5 & 255 & 9 \\
\hline & & & 1200 & 295 & 7 & 260 & 8 \\
\hline \multirow[t]{2}{*}{30 Jun } & 0411 (1211) & $1950(0350)$ & 0000 & 225 & 7 & 160 & 2 \\
\hline & & & 1200 & 320 & 14 & 220 & 10 \\
\hline \multirow[t]{2}{*}{$26 \mathrm{Jul}$} & 0435 (1235) & $1931(0331)$ & 0000 & 220 & 9 & 205 & 5 \\
\hline & & & 1200 & 290 & 14 & 180 & 3 \\
\hline \multirow[t]{2}{*}{14 Aug } & 0458 (1258) & 1904 (0304) & 0000 & 235 & 9 & 280 & 4 \\
\hline & & & 1200 & 280 & 8 & 295 & 7 \\
\hline \multirow[t]{2}{*}{15 Aug } & 0459 (1259) & 1902 (0302) & 0000 & 250 & 1 & 240 & 16 \\
\hline & & & 1200 & 295 & 9 & 210 & 7 \\
\hline \multirow[t]{2}{*}{16 Aug } & $0500(1300)$ & $1900(0300)$ & 0000 & 260 & 9 & 250 & 6 \\
\hline & & & 1200 & 325 & 13 & 160 & 4 \\
\hline \multirow[t]{2}{*}{17 Aug } & $0502(1302)$ & 1859 (0259) & 0000 & 355 & 4 & 245 & 3 \\
\hline & & & 1200 & 295 & 10 & 50 & 2 \\
\hline
\end{tabular}

these days (Table 3, which also shows sunrise and sunset at Hermiston and 700-mb rawinsonde winds at Salem and Spokane) were used to form the composites, to isolate common properties of these cases.

Near-surface, horizontal differences in pressure drive the flows through the gorge and over the basin, and reflect both large-scale and local-scale forcing. Figure $5 \mathrm{~b}$ shows the altimeter-setting difference between Astoria and Hermiston versus hour of the day for each of the eight days and for the composite mean. The composite pressure difference reached its lowest value $1-2 \mathrm{~h}$ after sunrise (1400 UTC), and then peaked in late afternoon (2300 UTC) after a day of surface heating. The amplitude of the diurnal curve, indicating the strength of the regional sea-breeze forcing, was similar for most of the days to within $\sim 1 \mathrm{hPa}$. The displacement of the daily mean of each curve, which amounted to $\sim 8 \mathrm{hPa}$, represents the large-scale forcing on which the diurnal fluctuation was superposed.

The primary driver of the diurnal wind systems in this region was SW radiation, measured at the four sites. Figure $5 \mathrm{c}$ shows the daily radiation as measured at Rufus, Oregon, a site along the Columbia River bank, for each of the eight days. Downward tics represent cloud effects, which were small and short lived when they occurred on these days. The overall smoothness of the curves thus indicates a significant lack of cloudiness. ${ }^{2}$ The variability among the curves

\footnotetext{
${ }^{2}$ A patch of cirrus clouds passed over the site after 0000 UTC 14 August, with little impact on the development of the regional sea breeze in the Columbia basin.
}

is dominated by the drop in solar angle from June to August.

\section{b. The marine intrusion: Composite analyses}

Time-height cross sections of the 8-day composite for each of the three sites are shown in Fig. 6. As on individual days, the leading edge of the late-afternoon flow accelerations occurred first at the westernmost site, Wasco, then Arlington, and finally Boardman. The presunrise lull in wind speeds below $200 \mathrm{~m}$ is evident during 1400-1500 UTC at Wasco, and weaker, shallower, and earlier at the other two sites. Daily minimum wind speeds coincided with daytime mixing between 1900 and 2200 UTC (1100-1400 local time) at all three sites.

Standard deviation $\left(\sigma_{\text {spd }}\right)$ plots (right panels, Fig. 6) show which aspects of the flow evolution had relatively consistent wind speeds from case to case and which aspects exhibited variability. Large evening values of $\sigma_{\text {spd }}$ from 2300 to 0400 UTC below $\sim 500 \mathrm{~m}$ are attributed to day-to-day variability in the timing of arrival of the sea-breeze/marine-intrusion front. This variability was seen at Wasco at 2300 UTC and amounted to $\sigma_{\text {spd }}$ $\sim 4 \mathrm{~m} \mathrm{~s}^{-1}$, but larger (and later) at Arlington $\left(5 \mathrm{~m} \mathrm{~s}^{-1}\right)$ and Boardman $\left(>5 \mathrm{~m} \mathrm{~s}^{-1}\right)$.

Time periods when wind speeds were consistent in the composite imply that one can forecast those wind speeds quantitatively and accurately (to within $\sigma_{\text {spd }}$ ), if one can forecast that a marine intrusion will occur, assuming these results are representative of marine intrusions in general. For example, all sites show small values of $\sigma_{\text {spd }}$ and therefore consistent wind speeds below $200 \mathrm{~m}$ for several hours around local midnight 

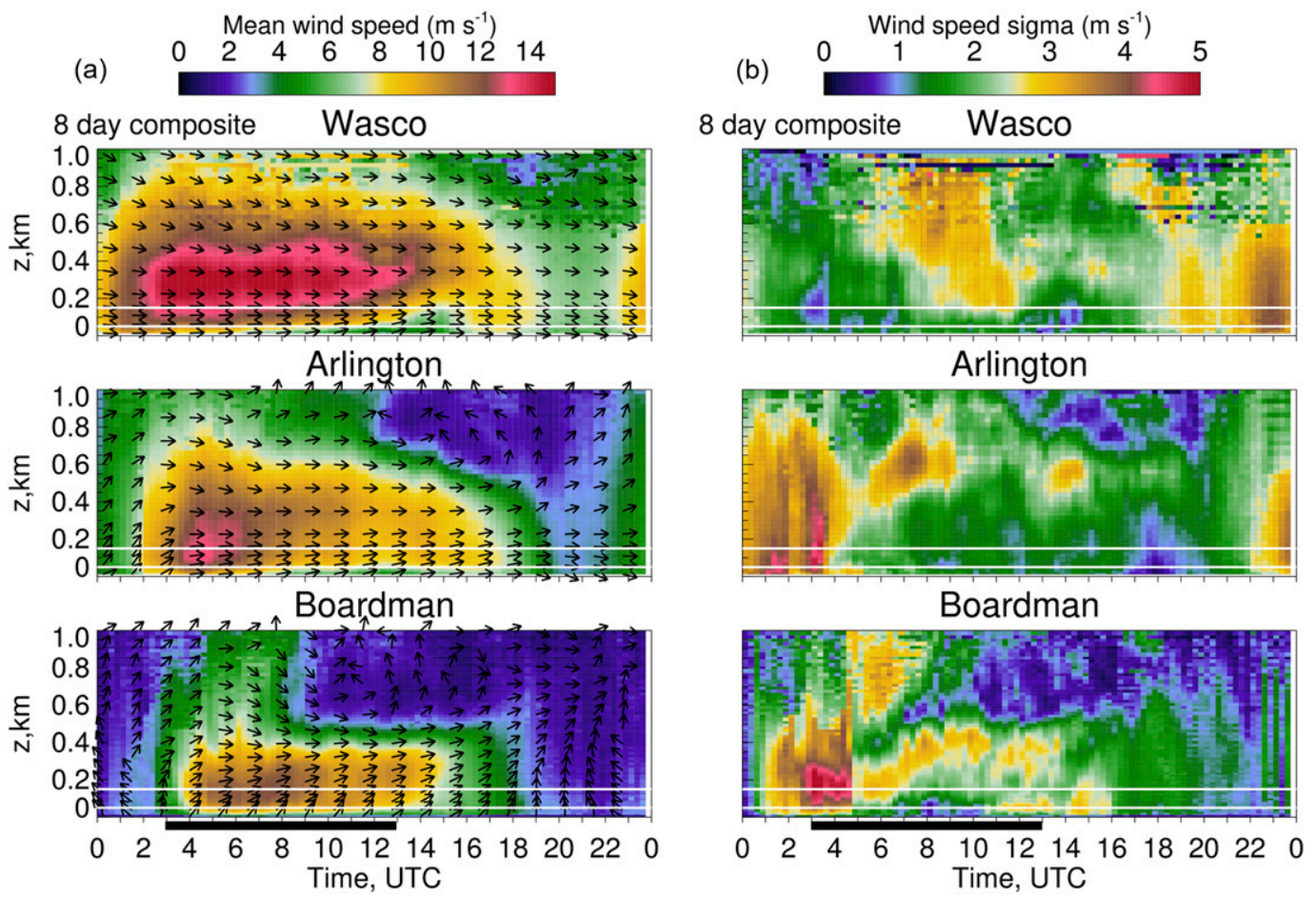

FIG. 6. Time-height cross sections of (a) mean wind speed and (b) wind speed standard deviation for each timeheight data point, composited for 8 days in summer of 2016, for the three lidar sites. Black lines along bottom axes indicate nighttime hours, black arrows show wind direction as in Fig. 4, and horizontal white parallel lines show turbine rotor layer.

(0800 UTC). If representative of the general case, such small standard deviations would indicate that, when marine intrusions occur, one can expect rotor-layer wind speeds of $11 \mathrm{~m} \mathrm{~s}^{-1}$ at Arlington and Boardman, and $12 \mathrm{~m} \mathrm{~s}^{-1}$ at Wasco, to within $\sigma_{\text {spd }}<2 \mathrm{~m} \mathrm{~s}^{-1}$ during these hours.

At Wasco the winds in the strong shear zone below $250 \mathrm{~m}$ from 0100 to 0700 UTC were relatively constant (within $\sim 1 \mathrm{~m} \mathrm{~s}^{-1}$ ) from day to day among the sample days, but this was not so at the other sites. This illustrates that, during some hours, winds can be consistent from event to event in one portion of the basin but not in other areas, even on clear, relatively undisturbed summer days.

The 100-m-AGL time series in Fig. 7 show more quantitatively how the wind systems in Fig. 6 impact flows near hub height in the turbine-rotor layer. The variability during the times of onset of the sea-breeze front is evident, as is the 0100-0700 UTC period of consistent wind speeds at Wasco noted above, and other periods at each site when the standard deviation dropped below $2 \mathrm{~m} \mathrm{~s}^{-1}$. The strong steadiness of the direction through most of the day, especially at Wasco and Arlington, seems remarkable, but is consistent with the bidirectional annual distribution found by Pichugina et al. (2019). Afternoon volatility to the wind direction after local noon (2000 UTC) is noted at Arlington and Boardman associated with the light winds at those sites.

Composite diurnal traces of altimeter differences between NWS station pairs along the Columbia River valley are shown in Fig. 8. The AST-HRI wavelike diurnal curve here was the mean (thick black) line in Fig. 5b. Of interest in Fig. 8a is that the trace for ASTPDX is nearly parallel to the AST-HRI curve. It was pointed out previously that the AST-HRI pressure difference is a major driver of the wind evolution. This plot shows that the shape of this diurnal fluctuation in the pressure gradient is similar whether observed near the coast between Astoria and Portland (from the shore to just inland), or between the coast and farther inland (see Fig. 8b). The other station-pair curves in Fig. 8a, which are between inland sites, show some variability, but much smaller than the 4-mb maximum-minimum spread in the AST-HRI and AST-PDX curves and out of phase with the major diurnal forcing. The PDXHRI curve in particular is relatively flat (amplitude $<$ $1 \mathrm{mb}$ ). These small variations probably reflect weaker complex-terrain effects that act as slight modifications to the dominant sea-breeze forcing, but do not fundamentally change its influence. Also noteworthy 
(a)
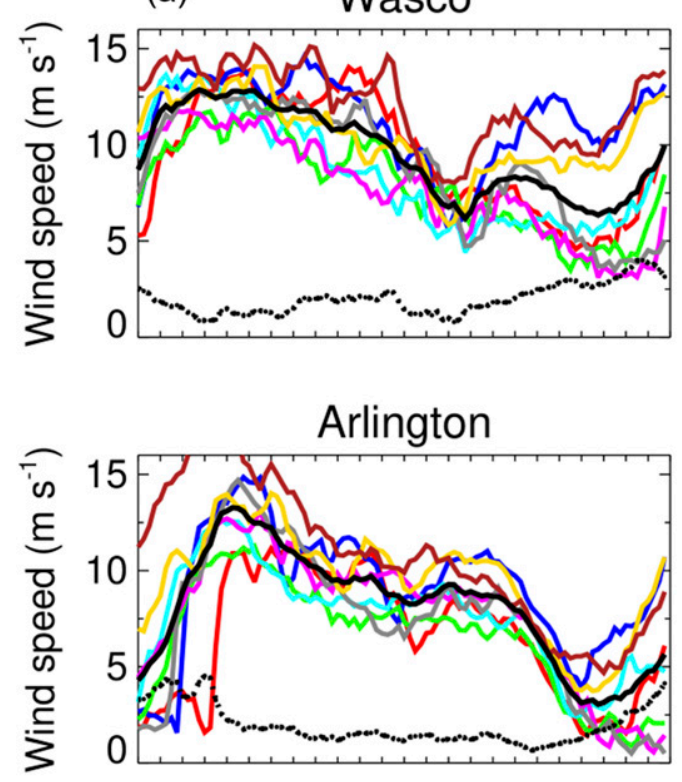

Boardman

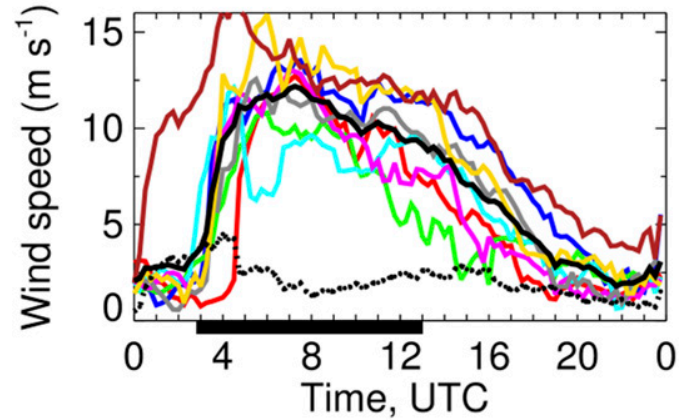

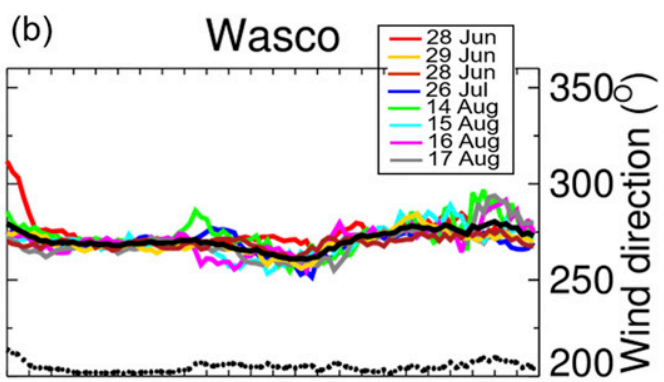

Arlington

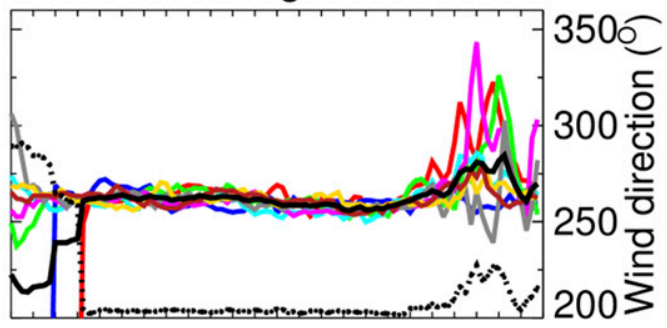

Boardman

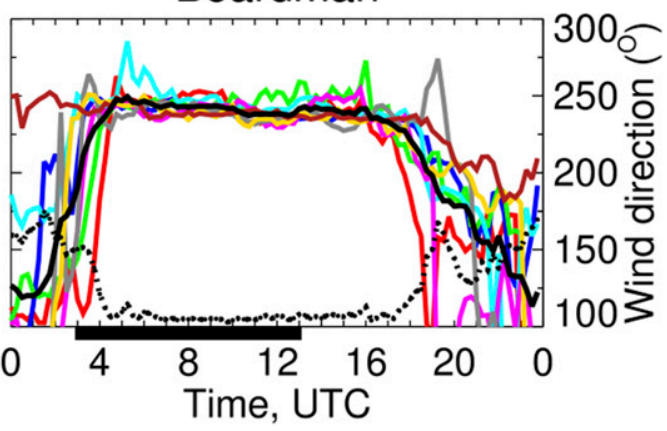

FIG. 7. Time series of lidar-measured 15-min (a) wind speed and (b) direction at $100 \mathrm{~m}$ AGL at (top) Wasco, (middle) Arlington, and (bottom) Boardman. Individual days are indicated by colored lines (see legend in top right panel). Thick black lines show composite means. Dotted line at the bottom of each panel gives the standard deviation of the eight values for each 15-min lidar measurement interval. Black lines along bottom axes indicate nighttime hours.

is the positive displacement of the mean of all the curves. This represents the large-scale pressure gradient below $\sim 1 \mathrm{~km}$, as described for Fig. 5b. California studies have emphasized that inland penetration of marine air behind sea-breeze fronts is maximized when diurnal sea-breeze forcing is superimposed on a significant large-scale, onshore-abetting pressure gradient (e.g., Fosberg and Schroeder 1966; Schroeder et al. 1967). The eight days studied here satisfy both conditions.

\section{HRRR evaluation versus Doppler lidar}

HRRR-model time-height cross sections of wind speed for forecast hours 1 and 3 are shown in Fig. 9 along with corresponding Doppler-lidar data (top row) for a representative marine-intrusion day, 17 August. Also shown in the lower panels of Fig. 9 are the model-minuslidar differences (i.e., the hourly model biases for the day) to show where, when, and how the model was consistent with or deviating from the measurements. Model-error statistics are calculated from this kind of daily difference data. Most obviously, large underpredictions by HRRR after 0600 UTC, sometimes more than $6 \mathrm{~m} \mathrm{~s}^{-1}$, resulted from the model ending the strong flow several hours too soon, especially at Arlington and Boardman. Earlier between 0000 and 0600 UTC the model had brought in the strong westerlies too soon (0100 UTC at Arlington and 0300 UTC at Boardman, as seen in the difference plots) and too strongly, leading to 
Station-pair pressure differences
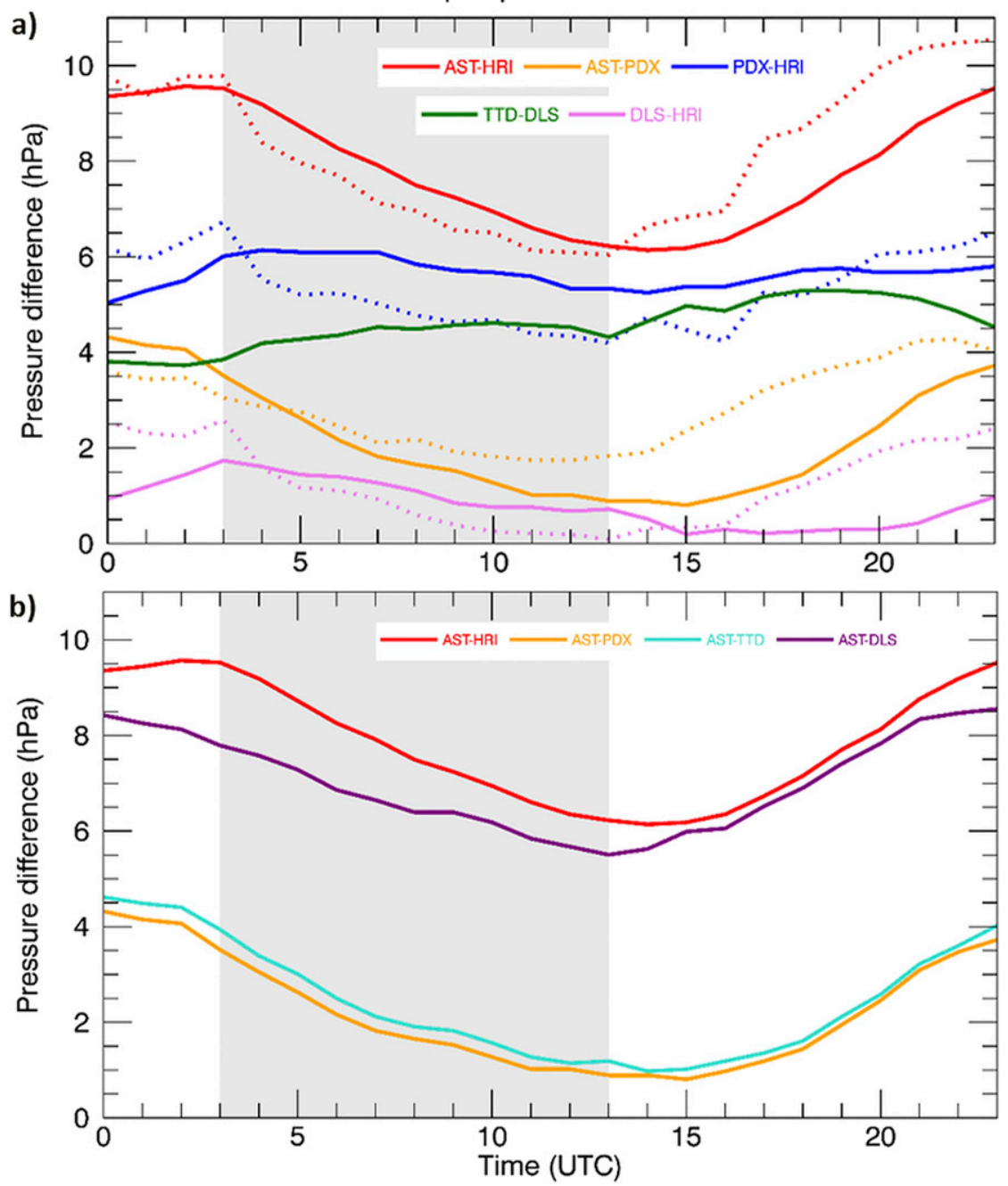

FIG. 8. Composite daily time series of altimeter pressure difference (hPa) between (a) indicated pairs of NWS Oregon stations, and (b) coastal Astoria and four inland stations. Solid lines indicate measured values, and dotted lines in (a) indicate HRRR-simulated values for the 3-h lead time forecast. The red (AST-HRI) and yellow (AST-PDX) curves are the same on both plots. Shading indicates approximate nighttime hours, represented by July time period.

positive errors, even more dramatically on some of the other days (not shown). Cross sections as presented here for hours 1 and 3 were plotted for all forecast hours out to $15 \mathrm{~h}$ (not shown). The error patterns for the longer lead times are very similar to those depicted in Figs. 9d and $9 \mathrm{e}$, consistent with the findings of Pichugina et al. (2019), that in this region, model skill does not degrade significantly with lead time out to $15 \mathrm{~h}$.

The HRRR model correctly predicted a marine intrusion in six of the eight cases. On 26 July and 14 August, the model winds were too light at Boardman, not meeting the $10 \mathrm{~m} \mathrm{~s}^{-1}$ threshold for all sites. In all, the model predicted 16 days that met the criteria for marine intrusions. The 10 days were incorrectly identified, mostly because of erroneously weak winds at Arlington the afternoon before, which met the $\leq 3 \mathrm{~m} \mathrm{~s}^{-1}$ threshold in the model but were stronger than this in the atmosphere.

Time-height composites of the diurnal HRRR error patterns provide a useful overview of HRRR's ability to model the 8-day mean flows at the three sites. Figure 10 shows the HRRR composites validated against the lidar cross sections, for the model 1- and 3-h forecasts. The composites resemble those of 17 August (Fig. 9), as anticipated. The lidar composites, repeated across the top row, are as in Fig. 6, except here show hourly data. They 

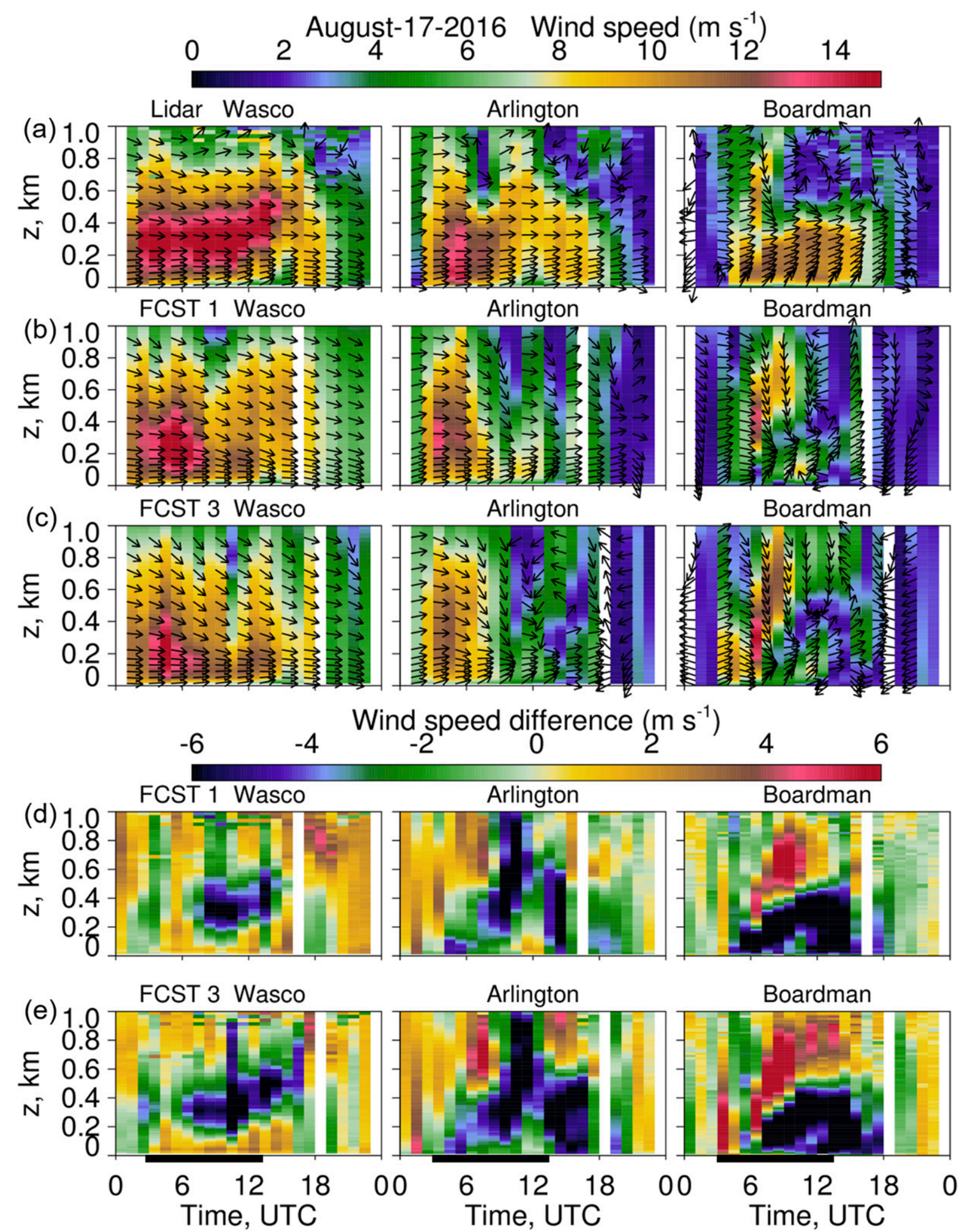

FIG. 9. Time-height cross sections of hourly mean wind speed (color coded, color bar at top) and wind direction (black arrows) at each site: (a) from lidar measurements, (b) from model forecast at lead hour 1, and (c) from model forecast at lead hour 3; (d),(e) biases between measured and modeled wind speed for the corresponding model forecast lead hours. Black arrows show wind direction as in Fig. 4, and black lines along bottom axes indicate nighttime hours. 


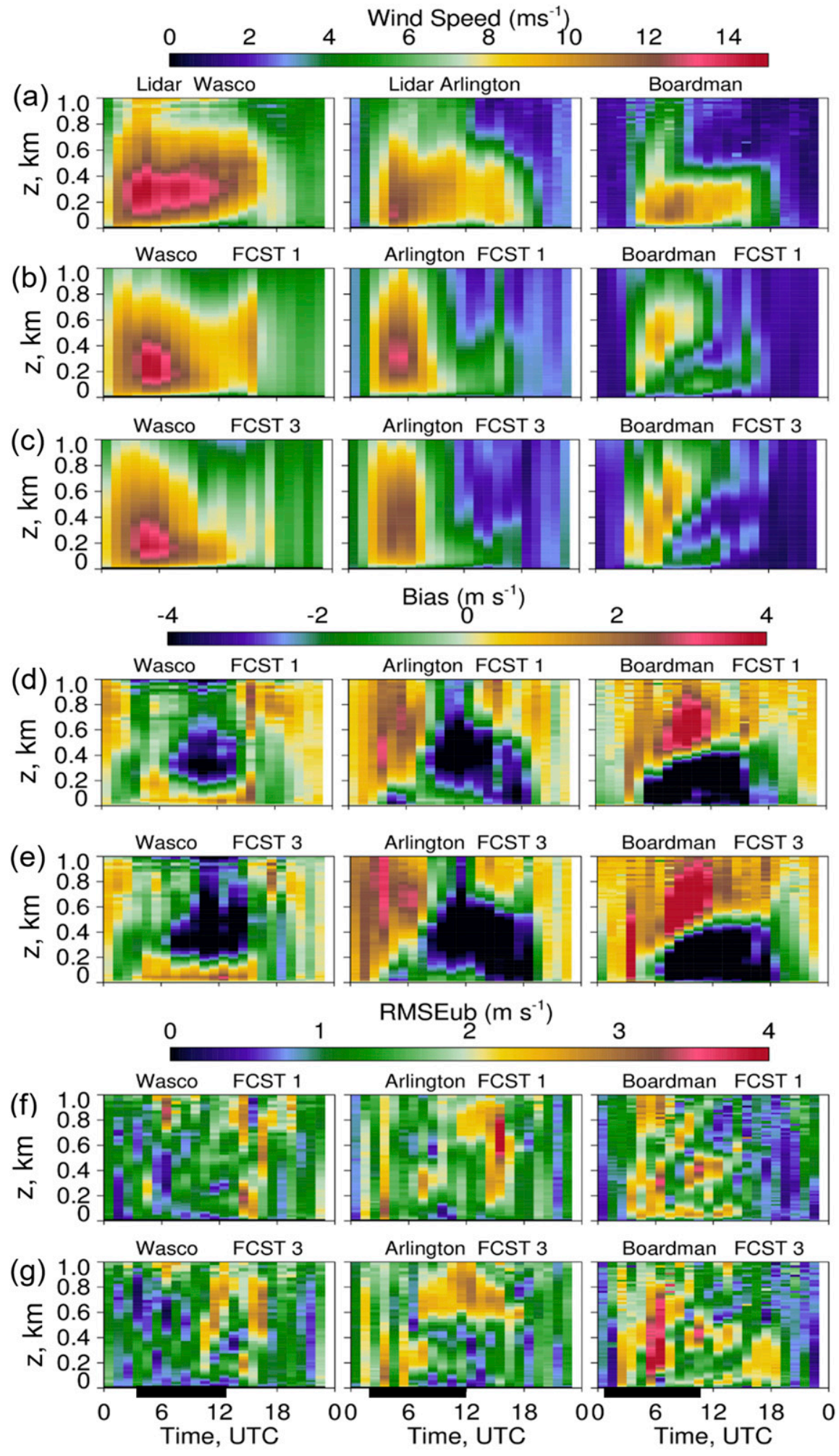

FIG. 10. Time-height cross sections of (a) Doppler-lidar measured wind speed composited for 8 days at Wasco, Arlington, and Boardman. (b) HRRR-modeled cross sections for 1-h lead time composited for the 8 days; (c) HRRR-modeled cross sections for 3-h lead time composited for the 8 days; (d) composited bias for model 1-h lead time; (e) composited bias for model 3-h lead time; (f) composited model unbiased RMS error for model 1-h lead time; and (g) composited model unbiased RMS error for model 3-h lead time. Black lines along bottom axes indicate nighttime hours. 
are followed by the HRRR composite forecasts, the model biases, and the unbiased RMSEs at the bottom. It is clear in the model composite that HRRR shut down the strong marine-intrusion flow too soon, as in Fig. 9. Specifically, the model failed to maintain the observed strong flows after 0600 UTC at each site through a 600-m-deep layer. The premature demise of the marine-layer westerlies was especially obvious at Arlington, producing model composite low biases exceeding $4 \mathrm{~m} \mathrm{~s}^{-1}$. At Wasco, the model did maintain stronger low-level winds below $150 \mathrm{~m}$, actually overpredicting them somewhat, but the bias cross section indicates large negative errors above that height, indicating that the too-abrupt weakening of the westerly flow noted for the other sites also happened at Wasco, except aloft.

Composite time series in Fig. 11 provide a more quantitative view of the model's ability to represent the flow evolution near turbine hub height as a function of hour of day, in this case for the model 3-h forecast. Shown are HRRR-model and lidar wind speeds at $100 \mathrm{~m}$ AGL at Wasco and Arlington, as well as time series of the bias and RMS errors (both biased and unbiased). The HRRR errors tended to be larger at Arlington for most of the hours, as the model underpredicted the wind speeds there by $2-4 \mathrm{~m} \mathrm{~s}^{-1}$. As was noted for Fig. 10, the large model low biases at Wasco happened above the 100-m-AGL level between 0600 and 1600 UTC, so model biases at $100 \mathrm{~m}$ there were less than $1 \mathrm{~m} \mathrm{~s}^{-1}$ in magnitude for much of the night. The presunrise dip in wind speeds from 1100 to 1200 UTC, and continuing through 1400 UTC, can be seen at Wasco, but the decline was relatively smooth in HRRR at this level.

Composite profiles of lidar-measured and modeled wind speed are shown in Fig. 12 for key hours, to illustrate the diurnal evolution of the vertical structure more quantitatively and in greater detail than discernible in Fig. 10. The top row shows the onset of the intrusionflow layer starting from well-mixed afternoon flow (2200 UTC) that was reasonably well represented in the model at each site. The premature acceleration of the HRRR-simulated flow at Arlington and Boardman is apparent between 0100 and 0300 UTC. This discrepancy was resolved by 0400 UTC, when strong LLJ-structured flow developed in the atmosphere as shown in the lidar profiles at those locations. The model thus anticipated the initiation of the strong flow at Arlington and Boardman, but brought it in too soon.

The middle row shows how the intrusion layer was maintained from 0600 to 1200 UTC in the measurements but not in HRRR. The measured profiles all exhibited LLJ structure: an $8 \mathrm{~m} \mathrm{~s}^{-1}$ maximum at mostly $\sim 200 \mathrm{~m}$ at Boardman, a broad $8 \mathrm{~m} \mathrm{~s}^{-1}$ peak centered around $300 \mathrm{~m}$ (Arlington), and $11 \mathrm{~m} \mathrm{~s}^{-1}$ at $300 \mathrm{~m}$ (Wasco). The depths of the intrusion layers were 800, 700, and $500 \mathrm{~m}$ at Wasco, Arlington, and, Boardman respectively, decreasing with distance from the Cascade barrier. At Boardman and Arlington, model profiles during this period show the vertical structure of the simulated spurious disappearance of the westerly LLJ flow below $400 \mathrm{~m}$. At Wasco the HRRR LLJ profiles had maxima at lower heights than observed. The Wasco profiles also show wind speed underpredictions above $150 \mathrm{~m}$ by as much as $4 \mathrm{~m} \mathrm{~s}^{-1}$ as noted previously, and the layer of winds below $150 \mathrm{~m}$ that were slightly stronger than observed, as described for Figs. 9 and 10.

The bottom row shows the continuation of strong (5$7 \mathrm{~m} \mathrm{~s}^{-1}$ ) LLJ structure at Boardman and Arlington in the measurements but not the model (1400-1500 UTC), and the presunrise lull's vertical structure below $200 \mathrm{~m}$ at Wasco (1500 UTC), also smoothed over in the model. The 1600-1800 UTC profiles show the morning mixout of the LLJ, the model systematically underpredicting the wind speeds by $1-4 \mathrm{~m} \mathrm{~s}^{-1}$.

HRRR-modeled pressure differences (reduced to sea level) for the NWS station pairs are compared with the altimeter-setting differences presented in Fig. 8a. Some systematic discrepancies are noted, such as the drop of the simulated values of the differences after sunset for AST-HRI and PDX-HRI, which may be related to the premature slackening of the winds at night, and the strong overprediction of the gradient for most of the pairs during the daylight hours. Further investigations into the reasons for the model-measurement discrepancies of the pressure differences is complicated, and beyond the scope of this study.

The primary forcing of the diurnal flow cycle is LW cooling and solar SW heating. Composite curves for SW radiation measured at the four radiometer sites are shown in black in Fig. 13, and symbols show hourly SW values simulated by the model (LW model values were unavailable). At the highest site, Condon, modeled and measured values agreed. Going down in elevation, the modeled midday values were too high at Wasco by $50 \mathrm{~W} \mathrm{~m}^{-2}$, and at the lowest site, Rufus, by $60 \mathrm{~W} \mathrm{~m}^{-2}$. A potential reason for the overprediction of SW and its elevation dependence is that HRRR does not predict or diagnose aerosol, whereas the atmosphere does contain aerosol, the largest concentrations generally occurring at lower levels. The surface temperature $T_{\text {sfc }}$ (blue) is related to the incoming SW radiation via the surface energy balance (SEB). Measured and modeled $T_{\mathrm{sfc}}$ show that this relationship was complicated, since the SW overpredictions at the lower sites were associated with 

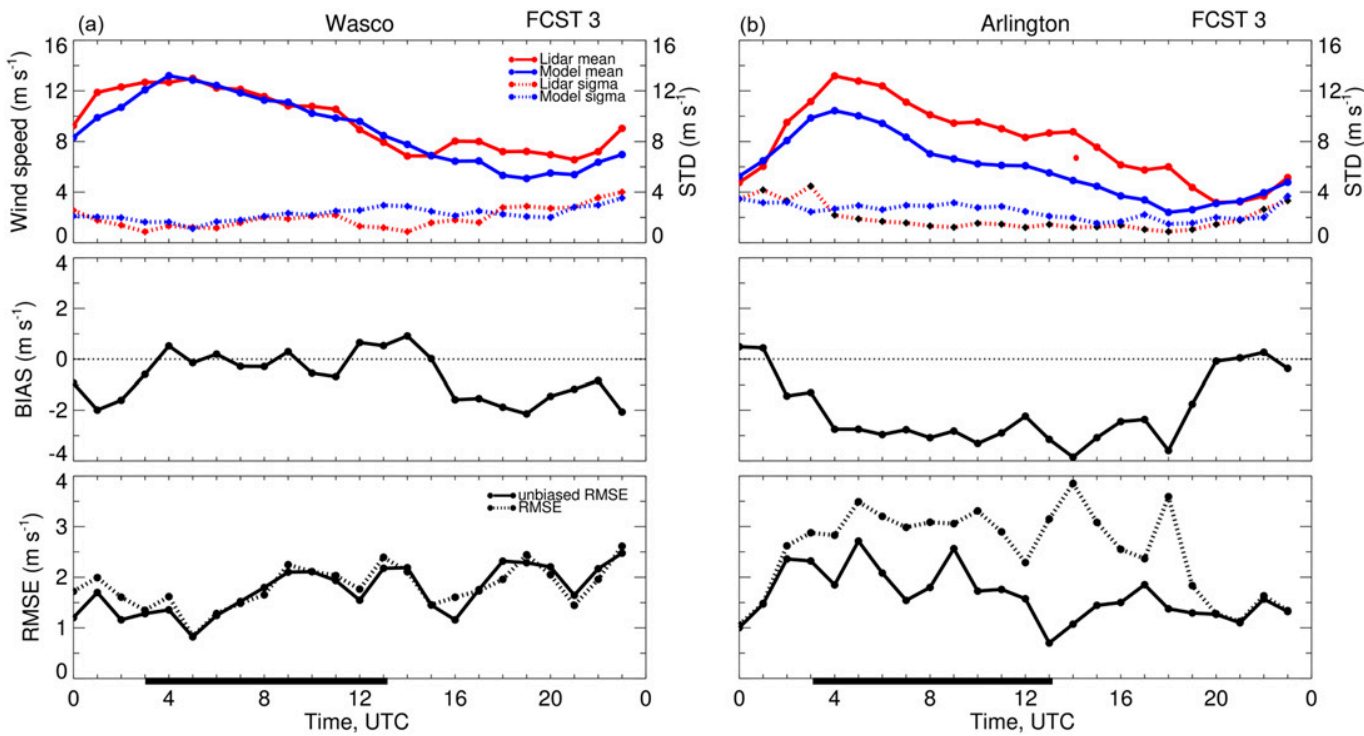

FIG. 11. (top) Solid lines with dot symbols show time series of 8-day mean wind speed at $100 \mathrm{~m}$ AGL as measured by lidar (red) and as simulated by HRRR at forecast-hour 3 (blue). Also shown are standard deviations of wind speed values at each hour for the 8 days (sigma, dashed lines with square symbols). (middle) Model bias ( $\mathrm{m} \mathrm{s}^{-1}$ ). (bottom) Model unbiased RMS error (solid black) and RMSE (dotted lines with square symbols). Black lines along bottom axes indicate nighttime hours.

overpredictions of $T_{\mathrm{sfc}}$, as might be expected, but at Condon, $T_{\text {sfc }}$ was underpredicted despite the good SW prediction. Solar-flux values and the model errors both vary from site to site, so it is of interest to determine how these SW radiation differences affect $T_{\mathrm{sfc}}$ and whether these radiation and temperature errors adversely affect the model's ability to predict the diurnal wind cycles in the basin.

Because of the critical role of near-surface horizontal temperature gradients in driving local thermally forced flows, the SEB is an obvious candidate for further study and model validation. We note that the SEB is itself a difficult measurement challenge. Recent analyses of field program data have used measured SEB data to compare with NWP models (e.g., Fernando et al. 2015; Massey et al. 2017).

\section{Seasonal and annual implications}

The composite analyses were from eight of the 92 days in June, July, and August 2016. Most of the other summer days saw cloud-free skies and strong insolation over the basin, and $62 \%$ of those days saw basin maximum temperatures of $30^{\circ} \mathrm{C}$ or more, in contrast to the oceansurface temperatures $\left(13^{\circ}-14^{\circ} \mathrm{C}\right)$ of the upwelling waters to the west. To investigate the generality of the marineintrusion pattern, Fig. 14 shows the 92-day composite time-height cross section for June-August 2016. The strong diurnal character of the wind speeds mimics the 8-day lidar-based cross sections. The intrusion flow was earliest, deepest, and strongest at Wasco, and latest, shallowest, and weakest at Boardman. In the model the intrusion-layer flow decelerated too soon after 0600 UTC, especially at Boardman and Arlington leading to low biases of $2 \mathrm{~m} \mathrm{~s}^{-1}$ in the lowest $200-300 \mathrm{~m}$. The routine sea-breeze forcing conditions over the basin thus generated a sufficiently recurrent flow response that the summer-long composites of wind speed reproduced the essential aspects of the 8-day composites-somewhat diluted in the average, as expected. The eight selected days were not anomalous with respect to typical summertime flow conditions over the basin. Also noteworthy, the summertime model composites showed error properties very similar to those seen in the 8-day composites, the effect again somewhat diluted, but indicating that model performance issues identified in the 8-day sample were repeatable enough through the summer to show up in the summer-long composite.

Recently Pichugina et al. (2019) used the WFIP2 lidar datasets to calculate longer-term wind statistics, including seasonal and annual HRRR error statistics for 2016. Figures 15a and 15c show the HRRR biases of wind speeds in the 50-150-m AGL layer as a function of forecast lead time for the summer and for the year of 2016 from that study. The summertime statistics in Fig. 15a show low biases reaching $1 \mathrm{~m} \mathrm{~s}^{-1}$ or more at Arlington and Boardman, and small-magnitude 

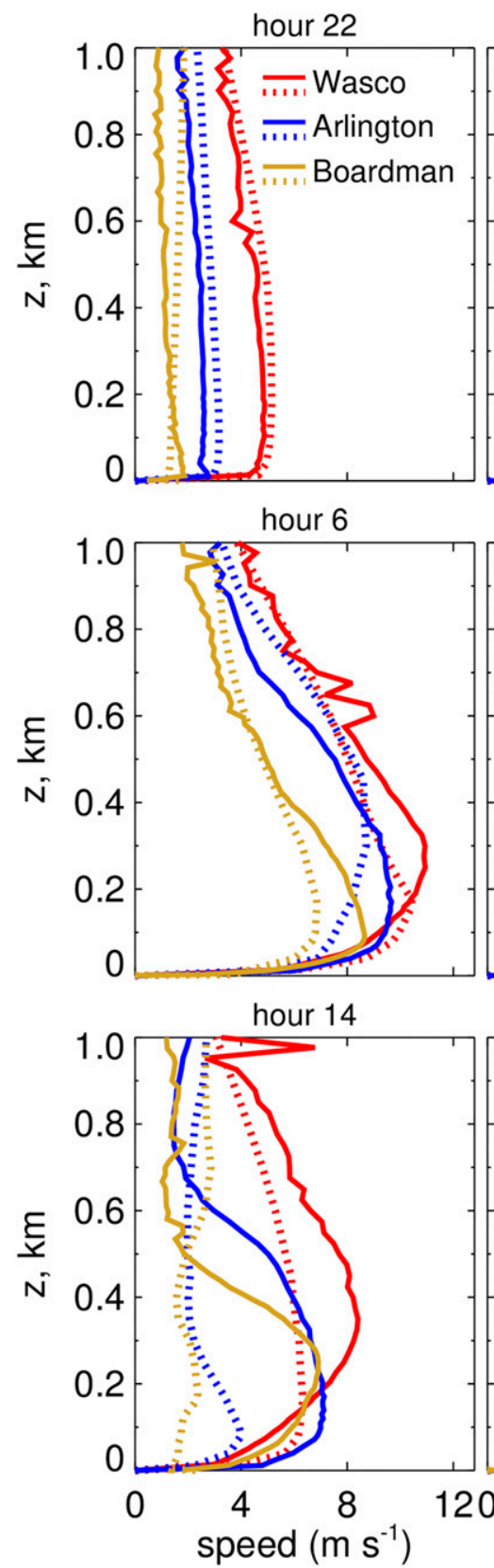

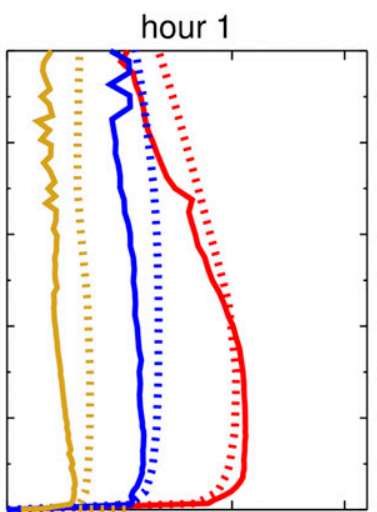

hour 8

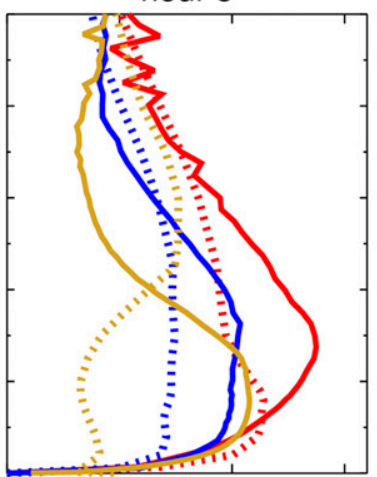

hour 15

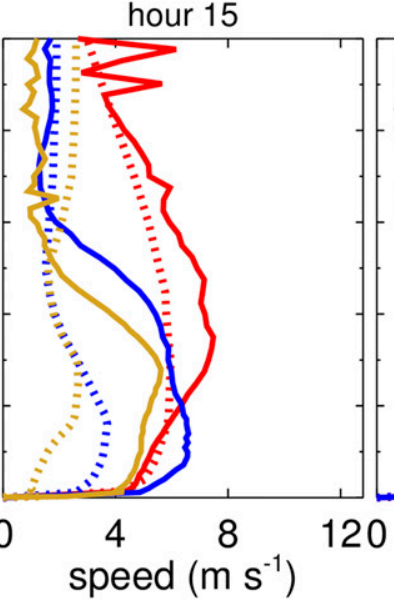

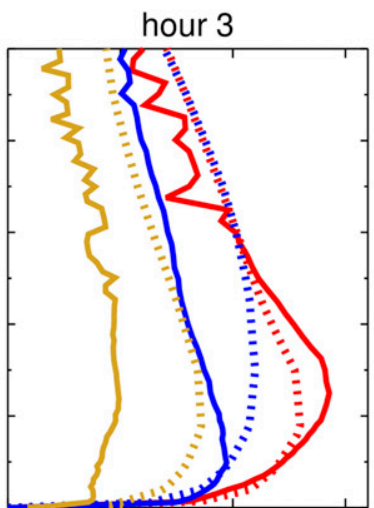

hour 9

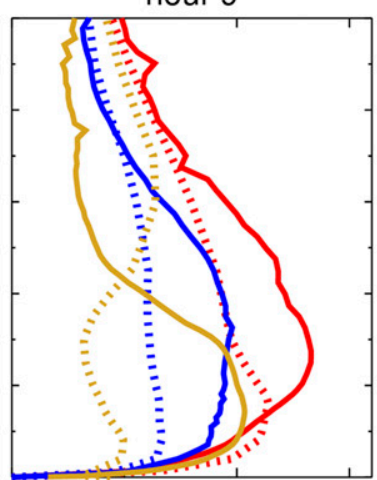

hour 16

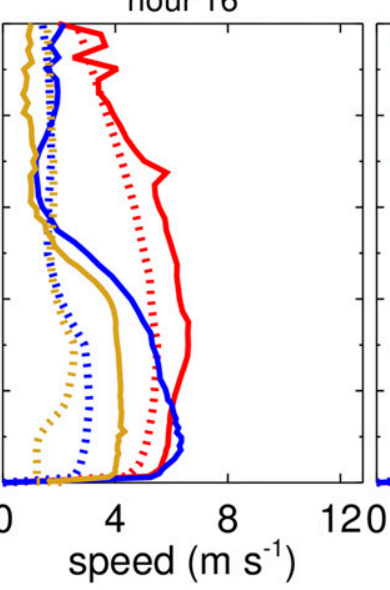

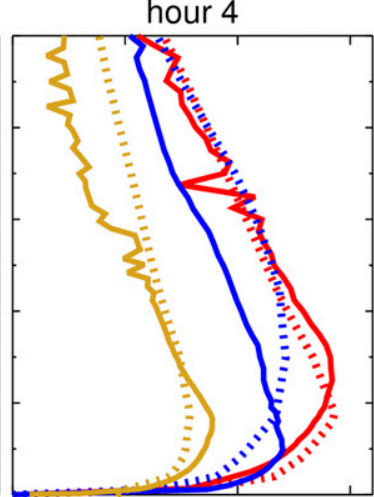

hour 12

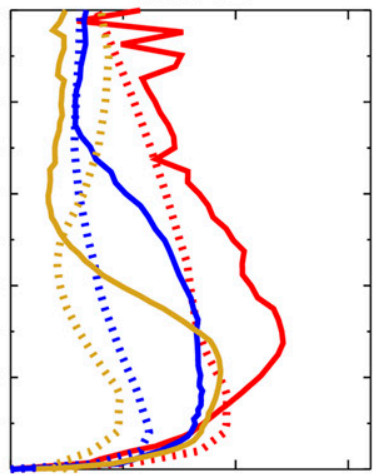

hour 18

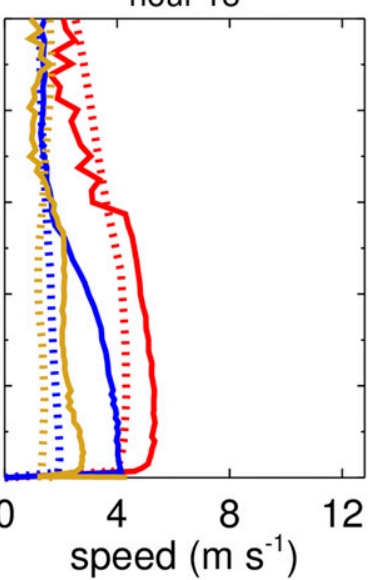

FIG. 12. Hourly 8-day composite wind speed profiles for selected UTC hours: lidar measured (solid); HRRR model forecast, for 3-h lead time (dotted). Profiles are color coded for each site according to the legend at the first panel of figure. Profile time (UTC) is specified at top of each panel.

values at Wasco, as found in Fig. 14. These results are actually representative of the warm-season half year. Interestingly, the biases for the entire year (Fig. 15c) also show these low biases at the two sites, but at about half the magnitude of the summer values. Biases during the winter at these sites are small $\left(<0.5 \mathrm{~m} \mathrm{~s}^{-1}\right)$ and positive (see Pichugina et al. 2019), so the negative annual biases must be from the warmseason model errors. As a function of hour of day
(Fig. 15b) the summertime low biases at Arlington and Boardman had the largest magnitudes at night, at times greater than $2 \mathrm{~m} \mathrm{~s}^{-1}$, due to HRRR's premature demise of the intrusion westerlies at those sites. These biases also appear in the annual statistics (Fig. 15d), again with about half the magnitude. That the errors and error patterns seen in the 8-day sample are also discernable in the annual error statistics implies that reducing the causes of those summertime 

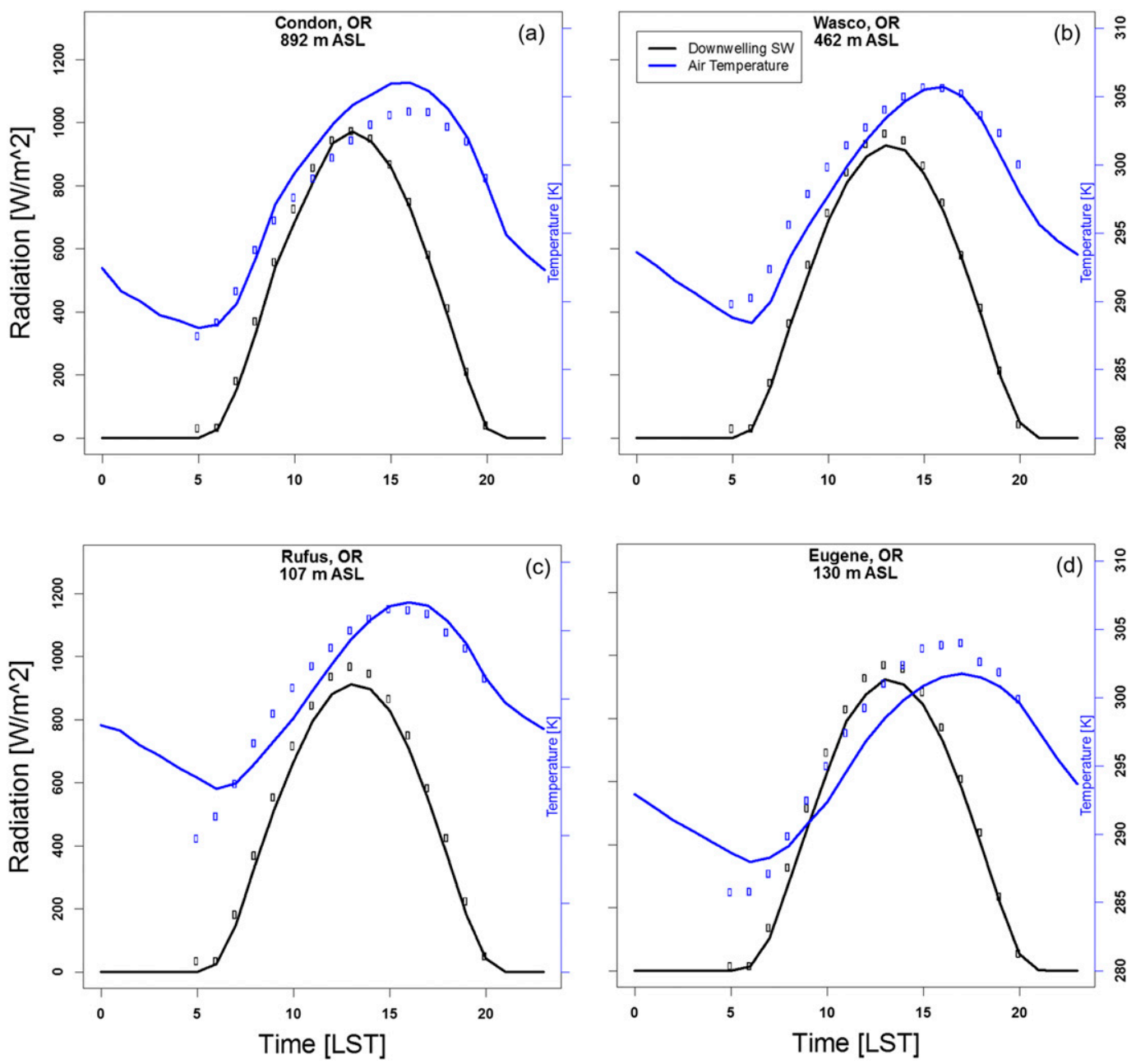

FIG. 13. Radiometer-measured downwelling shortwave radiation (black lines) at three sites in the Columbia basin and Eugene, OR, which is in the Willamette Valley just west of the Cascade Range. Open black symbols show HRRR hourly output SW radiation. Measured surface air temperature is the blue line at each site, and HRRR hourly temperature predictions are open blue circles. (a) Condon is the farthest south, then (b) Wasco, (c) Rufus, and (d) Eugene, OR, is west of the Cascade Range.

model errors would also improve the annual and longer-term error statistics.

\section{Discussion and recommendations}

Doppler lidar has been shown to provide insight into model errors. Data from multiple lidars allowed assessment of the horizontal representativeness of the errors and enabled diagnosis of features or aspects of the flow not being well represented in the model. This is a critical first step toward systematically determining how to improve models through measurements. It is also important to find out which simulated atmospheric processes have the greatest impact in generating the errors. The recurrent flows investigated here offer many advantages in sleuthing these errors. For the sea-breeze forcing, the physics are known. Several occurrences were found, and in each case the model generated similar errors. The flow and error properties thus were not unique to each case, as often found in the atmosphere; rather, they represented characteristic and repeatable traits of this type of flow, both in atmosphere and in model. Results can be generalized. Although we have concentrated here on the case-tocase similarities, one can also look at the differences among cases-can the model discriminate among them, and if not, why not?

The diurnal flows, and their associated errors, all took place below gradient-wind level, here represented by the 700-hPa height, where the winds differed among the cases. These wind variations indicate that the diurnal flows formed independently of these large-scale 

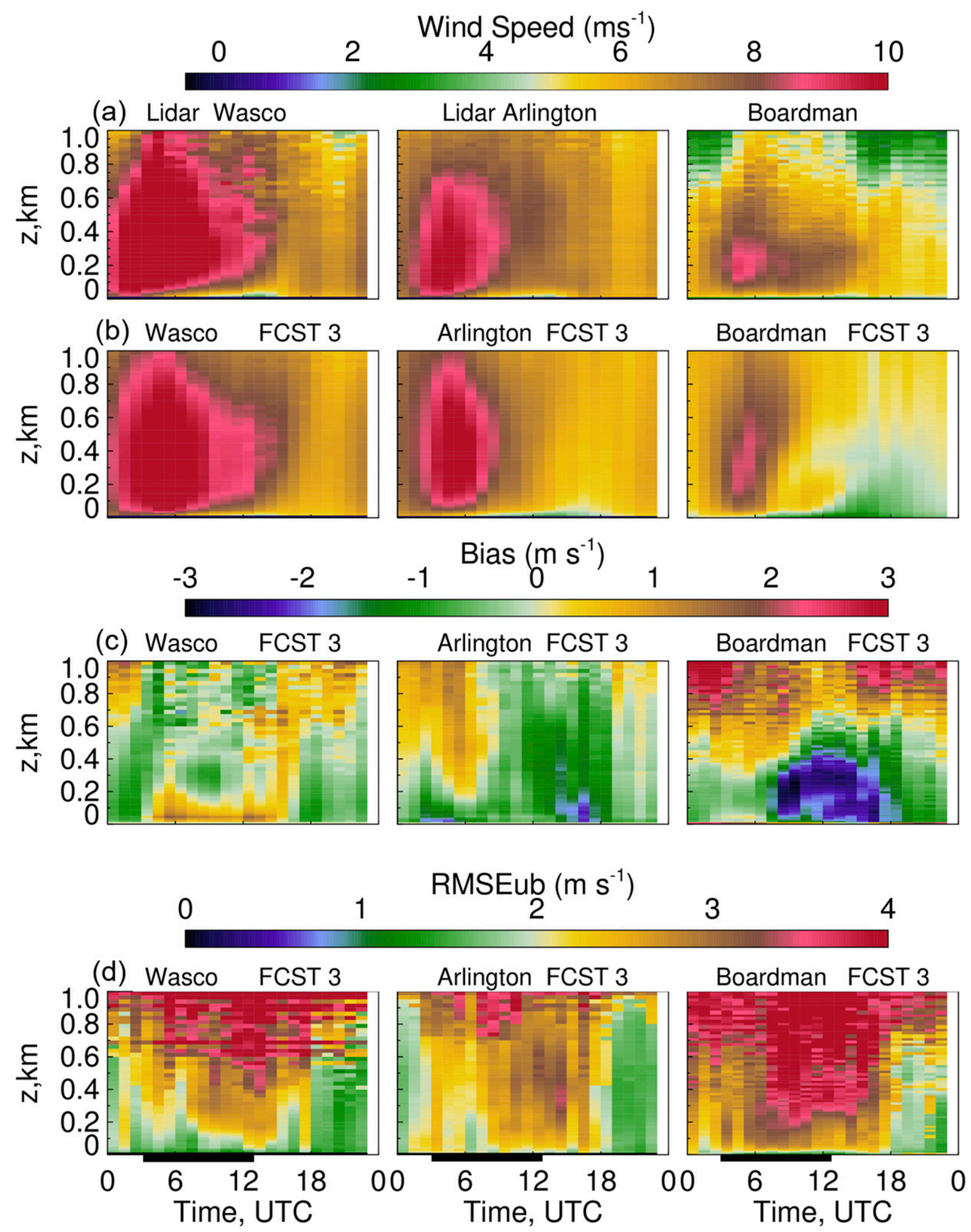

FIG. 14. Time-height cross sections of composite wind speed at three sites for the period covering the 92 days of June, July, and August 2016. (top) Lidar measurements; (second row) HRRR model simulations (3-h lead time); (third row) forecast bias; and (bottom) model unbiased RMSE. Black lines along bottom axes indicate nighttime hours. 

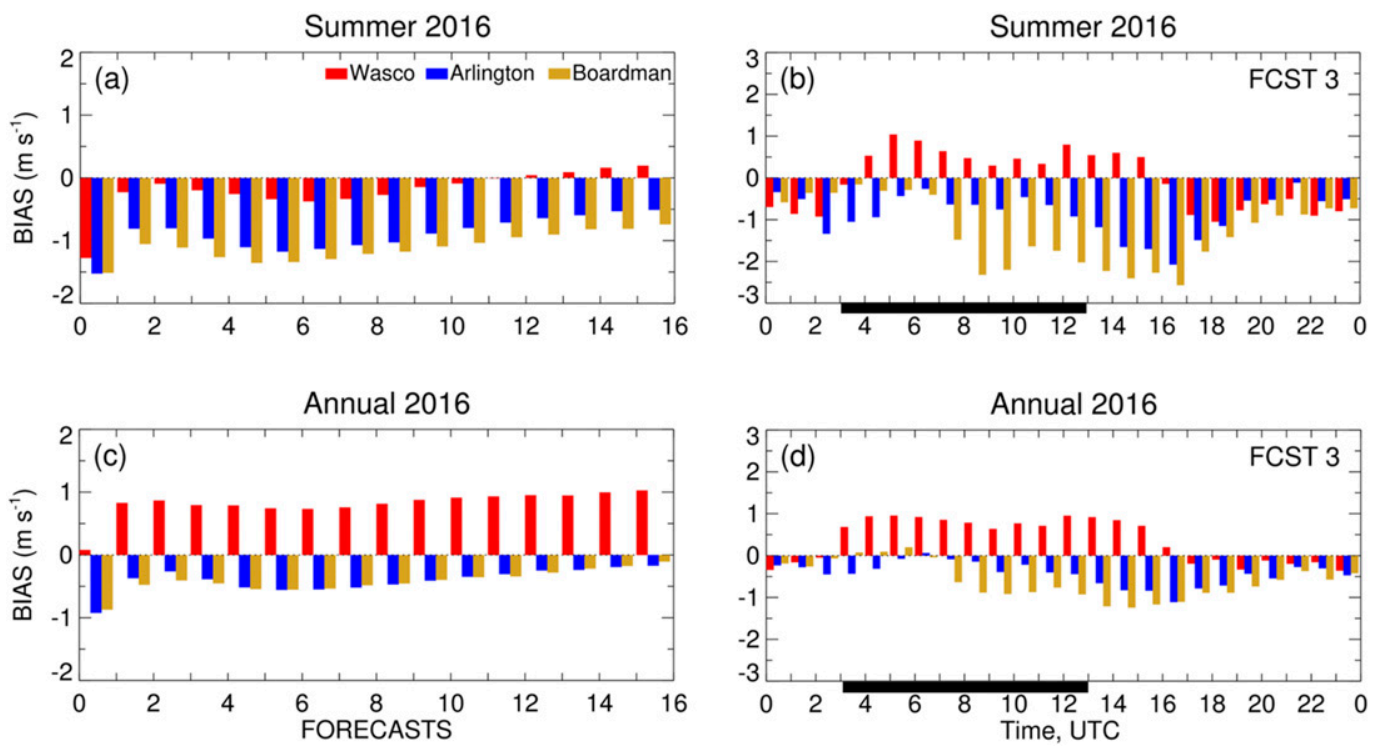

FIG. 15. (a) Summertime bias vs forecast lead-time hour for 92 days of June, July, August, averaged over the 50150-m AGL layer. (b) Summertime bias vs hour of day for June, July, and August 2016. Black line along bottom axis indicates approximate nighttime hours. (c) Annual bias vs forecast lead time hour, and (d) annual bias vs. forecast lead-time hour for 2016. All panels adapted from Pichugina et al. (2019).

conditions aloft. Induced by the offshore surface ridge, the important large-scale horizontal background forcing was the low-level pressure gradient across the Cascades, which also occurred mostly below gradient level, based on the same reasoning. The diurnalwind model errors detected at the lidar measurement sites thus had to be generated below gradient-wind level over a purlieu, a limited horizontal region, that included the coast and the Columbia basin. The 3D volume of atmosphere defined by these horizontal and vertical scales represents enough of a closed system, a natural laboratory, that model errors can be investigated therein.

An obvious recommendation is to densely instrument this volume with state-of-the-art instrumentation to document these recurrent flows as completely as currently possible. Considerations include:

- Wind profiles and model error profiles vary horizontally, so a dense enough array over the target area is required to capture this variability.

- Surface temperature, soil-layer properties, and SEB also vary significantly over the basin area, so this variability must also be understood, to assess errors introduced through the lower boundary.

- The larger-scale environments must also be documented, so nested arrays will be needed to measure all relevant scales of forcing (Banta et al. 2013).

The arrays would also assess model errors introduced via model initial conditions.
Physical processes that are important drivers of the recurrent flows over the limited region are likely to be the same physical processes whose misrepresentation limits forecast skill in general at longer time scales and over larger, even global, domains. Certainly boundary layer processes, the representation of clouds and cloud fields, ${ }^{3}$ and how the models handle the interactions between topography and the atmosphere are examples that have long been regarded as credible culprits in limiting NWP skill for models of all scales (e.g., Seaman 2000). It is likely that errors of the type, magnitude, and extent found in this study propagate ahead to degrade the longer-term forecasts downwind, thus limiting the longer-term skill of models at downstream locations.

\section{Conclusions: Recurrent flows and repeatable errors}

Diurnal marine-intrusion flows are an important wind-energy resource in summer. Their attributes are identifiable, repeatable, and potentially forecastable. They can be identified in seasonal and annual averages. Associated with these flows were characteristic

\footnotetext{
${ }^{3}$ Although moist processes were not an issue for these studies, cloud and cloud-field initiation cannot be properly simulated unless the modeled dry processes, which are of interest here, deliver accurate profiles of temperature, moisture, wind, and divergence (vertical velocity) to locations where the clouds form.
} 


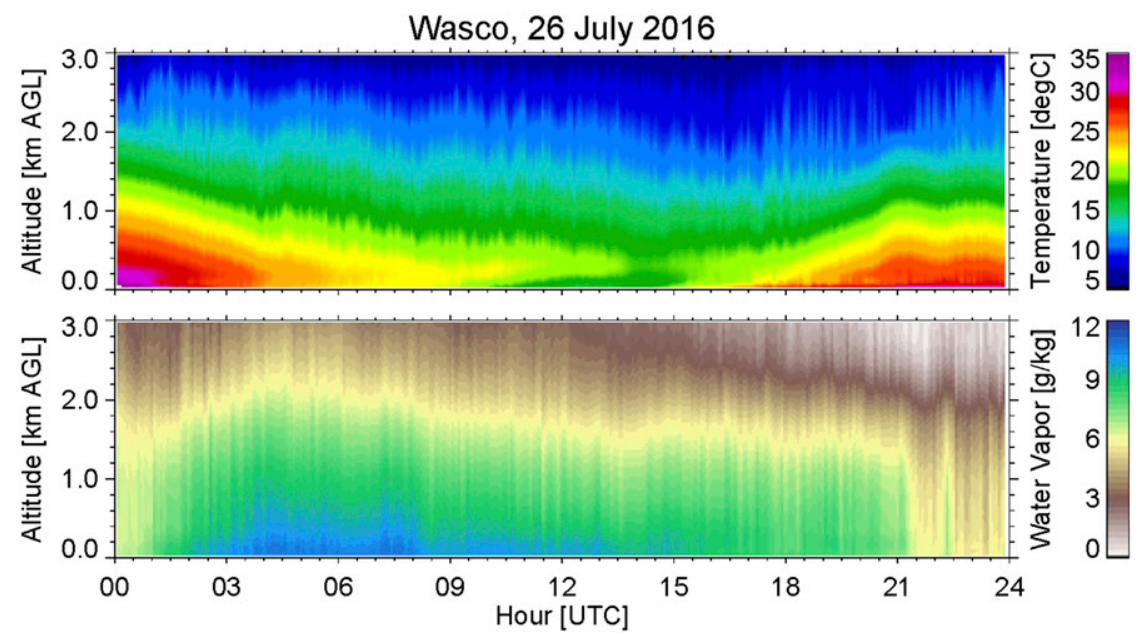

FIG. A1. Time-height cross sections of retrieved profiles of (top) temperature and (bottom) water vapor mixing ratio for $26 \mathrm{Jul} 2016$ at Wasco.

HRRR-model error "signatures": the same types of error occurred from case to case, and in the longerterm composites and averages. Essentially, each time these flows occurred the model made the same mistakes. These characteristic errors are clues as to where the models need improvement. The repeatable nature of the errors means that they are not due to a passing, one-time disturbance as often happens in the atmosphere, making error tracing so challenging, but these errors happen repeatedly, meaning that it should be possible to find out what causes them.

The logical next step is to use the new insights gained to recommend ways to improve models. The key finding here is the inference that the model errors were being generated within a limited region. If this is generally true, it makes it possible to investigate model errors by instrumenting the affected region-it is not necessary to instrument an entire continent, for example. This possibility makes the problem of model-error diagnosis and NWP-model improvement conceptually and practically tractable.

Acknowledgments. The authors thank the WFIP2experiment participants who aided in the deployment and the collection of lidar data. A special thanks goes to our colleagues Clark King from NOAA/ESRL/PSD, Ann Weickmann from CSD, and C. Hocut, Army Research Laboratory, for their preparation and deployment of lidars to the research sites. We also thank the journal reviewers, whose careful reading of our manuscript and helpful recommendations improved the quality and clarity of this paper. From NOAA/ESRL we thank Christina (Bonfanti) Kumler (GSD), Roy Miller (CSD), Brandi McCarty, (CSD), Chuck Long (GMD),
Gary Hodges (GMD), Emiel Hall (GMD), Jim Wendell (GMD), Melinda Marquis (GSD), and Chris Clack. Thanks also to Dr. Caroline Draxl for providing the base map for Fig. 1a, and Drs. Irina Djalalova and Laura Bianco for the microwave radiometer/RASS data. Eugene, Oregon, radiometer data were kindly provided by Dr. Frank Vignola of the University of Oregon. This work was sponsored by the NOAA/ESRL Air Quality Program, the Atmospheric Science for Renewable Energy (ASRE) Program, and NOAA was funded in part by the U.S. Department of Energy, Wind Energy Technologies Office, via DOE Grant DE-EE0007605.

\section{APPENDIX}

\section{Retrieved Microwave Radiometer/RASS Blended Temperature and Moisture Blended Profile Data: Time-Height Cross-Sectional Example}

Time-height cross sections of temperature and watervapor mixing ratio from the retrieved vertical profiles for 26 July 2016 are shown in Fig A1. The retrieval algorithm finds the solution that best matches the input data used in the retrieval using the approach described in Turner and Blumberg (2019). In particular, this retrieval used brightness temperature spectra observed by the microwave radiometer, the virtual temperature profiles observed by the radio acoustic sounding system (RASS), and the near-surface meteorological station as input. The water vapor cross section shows the moist layer moving in at $\sim 0100$ UTC and mixing out after 2100 UTC. A surface-based inversion layer (dark green) is shown to build up during the end of the nocturnal period between 1000 and 1400 UTC. Due to 
low information content in the microwave radiometer data, the vertical resolution of the retrieved profiles is relatively coarse at altitudes where the RASS data were not available (i.e., above $1 \mathrm{~km}$ ), and thus the retrieved profiles are smoothed vertically resulting in the layers appearing much deeper than they are in the atmosphere. However, the timing of the arrival and departure of the moist air is well captured, as is the timing of the cold-air layer buildup after 1000 UTC.

\section{REFERENCES}

Ahlstrom, M., and Coauthors, 2013: Knowledge is power: Efficiently integrating wind energy and wind forecasts. IEEE Power Energy Mag., 11, 45-52, https://doi.org/10.1109/MPE.2013.2277999.

American Wind Energy Association, 2018: U.S. wind industry annual market report, year ending 2017. American Wind Energy Association, $168 \mathrm{pp}$.

Atkinson, B. W., 1981: Meso-Scale Atmospheric Circulations. Academic Press, 495 pp.

Augustine, J. A., J. Deluisi, and C. N. Long, 2000: SURFRAD-A national surface radiation budget network for atmospheric research. Bull. Amer. Meteor. Soc., 81, 2341-2357, https:// doi.org/10.1175/1520-0477(2000)081<2341:SANSRB > 2.3.CO;2.

Banta, R. M., 1995: Sea breezes shallow and deep on the California coast. Mon. Wea. Rev., 123, 3614-3622, https://doi.org/10.1175/ 1520-0493(1995)123<3614:SBSADO > 2.0.CO;2.

_ 2008: Stable boundary layer regimes from the perspective of the low-level jet. Acta Geophys., 56, 58-87, https://doi.org/ 10.2478/s11600-007-0049-8.

_ L. D. Olivier, and D. H. Levinson, 1993: Evolution of the Monterey Bay sea-breeze layer as observed by pulsed Doppler lidar. J. Atmos. Sci., 50, 3959-3982, https://doi.org/10.1175/ 1520-0469(1993)050<3959:EOTMBS $>2.0 . C O ; 2$.

—, R. K. Newsom, J. K. Lundquist, Y. L. Pichugina, R. L. Coulter, and L. Mahrt, 2002: Nocturnal low-level jet characteristics over Kansas during CASES-99. Bound.-Layer Meteor., 105, 221-252, https://doi.org/10.1023/A:1019992330866.

_ , and Coauthors, 2005: A bad air day in Houston. Bull. Amer. Meteor. Soc., 86, 657-670, https://doi.org/10.1175/BAMS-86-5-657.

- , Y. L. Pichugina, N. D. Kelley, W. A. Brewer, and R. M. Hardesty, 2013: Wind-energy meteorology: Insight into wind properties in the turbine rotor layer of the atmosphere from high-resolution Doppler lidar. Bull. Amer. Meteor. Soc., 94, 883-902, https://doi.org/10.1175/BAMS-D-11-00057.1.

_ , and Coauthors, 2015: 3-D volumetric analysis of wind-turbine wake properties in the atmosphere using high-resolution Doppler lidar. J. Atmos. Oceanic Technol., 32, 904-914, https://doi.org/10.1175/JTECH-D-14-00078.1.

_ , and Coauthors, 2018: Evaluating and improving NWP forecasts for the future: How the needs of offshore wind energy can point the way. Bull. Amer. Meteor. Soc., 99, 1155-1176, https://doi.org/10.1175/BAMS-D-16-0310.1.

Barthelmie, R. J., and Coauthors, 2014: 3D wind and turbulence characteristics of the atmospheric boundary layer. Bull. Amer. Meteor. Soc., 95, 743-756, https://doi.org/10.1175/BAMS-D 12-00111.1.

Benjamin, S. G., and Coauthors, 2016: A North American hourly assimilation and model forecast cycle: The Rapid Refresh. Mon. Wea. Rev., 144, 1669-1694, https://doi.org/10.1175/ MWR-D-15-0242.1.
Bonin, T. A., and Coauthors, 2015: Thermodynamic and turbulence characteristics of the Southern Great Plains nocturnal boundary layer under differing turbulent regimes. Bound.Layer Meteor., 157, 401-420, https://doi.org/10.1007/s10546015-0072-2.

Brewer, M. C., and C. F. Mass, 2014: Simulation of summer diurnal circulations over the northwest United States. Wea. Forecasting, 29, 1208-1228, https://doi.org/10.1175/WAF-D-1400018.1.

Browning, K. A., and R. Wexler, 1968: The determination of kinematic properties of a wind field using Doppler radar. J. Appl. Meteor., 7, 105-113, https://doi.org/10.1175/1520-0450(1968) 007<0105:TDOKPO $>2.0 . \mathrm{CO} ; 2$.

Carroll, B. J., B. B. Demoz, and R. Delgado, 2019: An overview of low-level jet winds and corresponding mixed layer depths during PECAN. J. Geophys. Res. Atmos., 124, 9141-9160, https://doi.org/10.1029/2019JD030658.

Chen, G., H. Iwai, S. Ishii, K. Saito, H. Seko, W. Sha, and T. Iwasaki, 2019: Structures of the sea-breeze front in dual-Doppler lidar observation and coupled mesoscale-to-LES modeling. J. Geophys. Res. Atmos., 124, 2397-2413, https://doi.org/ 10.1029/2018JD029017.

Clark, T. L., W. D. Hall, and R. M. Banta, 1994: Two- and threedimensional simulations of the 9 January 1989 windstorm: Comparison with observations. J. Atmos. Sci., 51, 2317-2343, https://doi.org/10.1175/1520-0469(1994)051<2317:TATDSO > 2.0.CO;2.

Crosman, E. T., and J. D. Horel, 2010: Sea and lake breezes: A review of numerical studies. Bound.-Layer Meteor., 137, 1-29, https://doi.org/10.1007/s10546-010-9517-9.

Darby, L. S., and G. S. Poulos, 2006: The evolution of lee wave/ rotor activity in the lee of Pike's Peak under the influence of a cold frontal passage: Implications for aircraft safety. Mon. Wea. Rev., 134, 2857-2876, https://doi.org/10.1175/MWR3208.1. , and Coauthors, 2002a: Vertical variations in $\mathrm{O}_{3}$ concentrations before and after a gust front passage. J. Geophys. Res., 107, 4176, https://doi.org/10.1029/2001JD000996.

R. M. Banta, and R. A. Pielke, 2002b: Comparisons between mesoscale model terrain sensitivity studies and Doppler lidar measurements of the sea breeze at Monterey Bay. Mon. Wea. Rev., 130, 2813-2838, https://doi.org/10.1175/1520-0493(2002) 130<2813:CBMMTS >2.0.CO;2.

— , and Coauthors, 2007: Ozone differences between nearcoastal and offshore sites in New England: Role of meteorology. J. Geophys. Res., 112, D16S91, https://doi.org/10.1029/ 2007JD008446.

Defant, F., 1951: Local winds. Compendium of Meteorology, T. Malone, Ed., Amer. Meteor. Soc., 655-672.

Djalalova, I. V., and Coauthors, 2016: The POWER experiment: Impact of assimilation of a network of coastal wind profiling radars on simulating offshore winds in and above the wind turbine layer. Wea. Forecasting, 31, 1071-1091, https://doi.org/ 10.1175/WAF-D-15-0104.1.

Doran, J. C., and S. Zhong, 1994: Regional drainage flows in the Pacific Northwest. Mon. Wea. Rev., 122, 1158-1167, https:// doi.org/10.1175/1520-0493(1994)122<1158:RDFITP>2.0.CO;2.

Emeis, S., M. Harris, and R. M. Banta, 2007: Boundary-layer anemometry by optical remote sensing for wind energy applications. Meteor. Z., 16, 337-347, https://doi.org/10.1127/ 0941-2948/2007/0225.

Fernández-González, S., M. L. Martín, E. García-Ortega, A. Merino, J. Lorenzana, J. L. Sánchez, F. Valero, and J. S. Rodrigo, 2018: Sensitivity analysis of the WRF model: 
Wind-resource assessment for complex terrain. J. Appl. Meteor. Climatol., 57, 733-753, https://doi.org/10.1175/ JAMC-D-17-0121.1.

Fernando, H. J. S., and Coauthors, 2015: The MATERHORN: Unraveling the intricacies of mountain weather. Bull. Amer. Meteor. Soc., 96, 1945-1967, https://doi.org/10.1175/ BAMS-D-13-00131.1.

, and Coauthors, 2019: The Perdigão: Peering into microscale details of mountain winds. Bull. Amer. Meteor. Soc., 100, 799819, https://doi.org/10.1175/BAMS-D-17-0227.1.

Fosberg, M. A., and M. J. Schroeder, 1966: Marine air penetration in Central California. J. Appl. Meteor., 5, 573-589, https:// doi.org/10.1175/1520-0450(1966)005<0573:MAPICC >2.0.CO;2.

Gilliam, R. C., S. Raman, and D. D. S. Niyogi, 2004: Observational and numerical study on the influence of large-scale flow direction and coastline shape on sea-breeze evolution. Bound.-Layer Meteor., 111, 275-300, https://doi.org/10.1023/ B:BOUN.0000016494.99539.5a.

Gohm, A., G. J. Mayr, L. S. Darby, and R. M. Banta, 2010: Evolution and structure of a cold front in an Alpine valley as revealed by a Doppler lidar. Quart. J. Roy. Meteor. Soc., 136, 962-977, https://doi.org/10.1002/QJ.609.

Grund, C. J., R. M. Banta, J. L. George, J. N. Howell, M. J. Post, R. A. Richter, and A. M. Weickmann, 2001: High-resolution Doppler lidar for boundary layer and cloud research. J. Atmos. Oceanic Technol., 18, 376-393, https://doi.org/10.1175/15200426(2001)018<0376:HRDLFB > 2.0.CO;2.

Holland, G. J., and J. L. McBride, 1989: Quasi-trajectory analysis of a sea-breeze front. Quart. J. Roy. Meteor. Soc., 115, 571580, https://doi.org/10.1002/qj.49711548708.

Hu, X.-M., and M. Xue, 2016: Influence of synoptic sea-breeze fronts on the urban heat island intensity in Dallas-Fort Worth, Texas. Mon. Wea. Rev., 144, 1487-1507, https://doi.org/10.1175/ MWR-D-15-0201.1.

Iacono, M. J., J. S. Delamere, E. J. Mlawer, M. W. Shephard, S. A. Clough, and W. D. Collins, 2008: Radiative forcing by longlived greenhouse gases: Calculations with the AER radiative transfer models. J. Geophys. Res., 113, D13103, https://doi.org/ 10.1029/2008JD009944.

Intrieri, J. M., A. J. Bedard Jr., and R. M. Hardesty, 1990: Details of colliding thunderstorm outflows as observed by Doppler lidar. J. Atmos. Sci., 47, 1081-1099, https://doi.org/10.1175/ 1520-0469(1990)047<1081:DOCTOA>2.0.CO;2.

Johnson, A., Jr., and J. J. O'Brien, 1973: A study of an Oregon sea breeze event. J. Appl. Meteor., 12, 1267-1283, https://doi.org/ 10.1175/1520-0450(1973)012<1267:ASOAOS >2.0.CO;2.

Klaas, T., L. Pauscher, and D. Callies, 2015: LiDAR-mast deviations in complex terrain and their simulation using CFD. Meteor. Z., 24, 591-603, https://doi.org/10.1127/metz/ 2015/0637.

Lhermitte, R., and D. Atlas, 1961: Precipitation motion by pulse Doppler radar. Preprints, Ninth Conf. on Radar Meteorology, Kansas City, MO, Amer. Meteor. Soc., 218-223.

Long, C. N., and T. P. Ackerman, 2000: Identification of clear skies from broadband pyranometer measurements and calculation of downwelling shortwave cloud effects. J. Geophys. Res., 105, 15 609-15 626, https://doi.org/10.1029/2000JD900077.

, — - K. L. Gaustad, and J. N. S. Cole, 2006: Estimation of fractional sky cover from broadband shortwave radiometer measurements. J. Geophys. Res., 111, D11204, https://doi.org/ 10.1029/2005JD006475.

Mass, C. F., M. D. Albright, and D. J. Brees, 1986: The onshore surge of marine air into the Pacific Northwest: A coastal region of complex terrain. Mon. Wea. Rev., 114, 2602-2627, https://doi.org/10.1175/1520-0493(1986)114<2602:TOSOMA> 2.0.CO;2.

Massey, J. D., W. J. Steenburgh, S. W. Hoch, and D. D. Jensen, 2017: Simulated and observed surface energy fluxes and resulting playa breezes during the MATERHORN field campaign. J. Appl. Meteor. Climatol., 56, 915-935, https://doi.org/ 10.1175/JAMC-D-16-0161.1.

Mayor, S. D., 2011: Observations of seven atmospheric density current fronts in Dixon, California. Mon. Wea. Rev., 139, 1338-1351, https://doi.org/10.1175/2010MWR3374.1.

Miller, S. T. K., B. D. Keim, R. W. Talbot, and H. Mao, 2003: Sea breeze: Structure, forecasting, and impacts. Rev. Geophys., 41, 1011, https://doi.org/10.1029/2003RG000124.

Nakane, H., and Y. Sasano, 1986: Structure of a sea-breeze front as revealed by a scanning lidar observation. J. Meteor. Soc. Japan, 64, 787-792, https://doi.org/10.2151/jmsj1965.64.5_ 787.

Nakanishi, M., and H. Niino, 2009: Development of an improved turbulence closure model for the atmospheric boundary layer. J. Meteor. Soc. Japan, 87, 895-912, https://doi.org/10.2151/ jmsj.87.895.

Neiman, P. J., D. J. Gottas, and A. B. White, 2019: A two-coolseason wind profiler based analysis of westward-directed gap flow through the Columbia River Gorge. Mon. Wea. Rev., 147, 4653-4680, https://doi.org/10.1175/MWR-D-19-0026.1.

Newsom, R. K., and R. M. Banta, 2003: Shear-flow instability in the stable nocturnal boundary layer as observed by Doppler lidar during CASES-99. J. Atmos. Sci., 60, 16-33, https://doi.org/ 10.1175/1520-0469(2003)060<0016:SFIITS >2.0.CO;2.

Olson, J., J. S. Kenyon, W. M. Angevine, J. M. Brown, M. Pagowski, and K. Sušelj, 2019a: A description of the MYNN-EDMF scheme and coupling to other components in WRF-ARW. NOAA Tech. Memo. OAR GSD 61, 37 pp., https://doi.org/ 10.25923/n9wm-be49.

_ , and Coauthors, 2019b: Improving wind energy forecasting through numerical weather prediction model development. Bull. Amer. Meteor. Soc., 100, 2201-2220, https://doi.org/ 10.1175/BAMS-D-18-0040.1.

Olsson, L. E., W. P. Elliott, and S.-I. Hsu, 1973: Marine air penetration in western Oregon: An observational study. Mon. Wea. Rev., 101, 356-362, https://doi.org/10.1175/1520-0493(1973) $101<0356$ :MAPIWO $>2.3$.CO;2.

Pearson, G., F. Davies, and C. Collier, 2009: An analysis of the performance of the UFAM pulsed Doppler lidar for observing the boundary layer. J. Atmos. Oceanic Technol., 26, 240-250, https://doi.org/10.1175/2008JTECHA1128.1.

Peckham, S. E., T. G. Smirnova, S. G. Benjamin, J. M. Brown, and J. S. Kenyon, 2016: Implementation of a digital filter initialization in the WRF model and its application in the Rapid Refresh. Mon. Wea. Rev., 144, 99-106, https://doi.org/10.1175/ MWR-D-15-0219.1.

Pichugina, Y. L., and R. M. Banta, 2010: Stable boundary-layer depth from high-resolution measurements of the mean wind profile. J. Appl. Meteor. Climatol., 49, 20-35, https://doi.org/ 10.1175/2009JAMC2168.1.

— , and Coauthors, 2017a: Properties of offshore low-level jet and rotor layer wind shear as measured by scanning Doppler lidar. Wind Energy, 20, 987-1002, https://doi.org/10.1002/ we. 2075 .

— , and Coauthors, 2017b: Assessment of NWP forecast models in simulating offshore winds through the lower boundary layer by measurements from a ship-based scanning Doppler 
lidar. Mon. Wea. Rev., 145, 4277-4301, https://doi.org/10.1175/ MWR-D-16-0442.1.

— , and Coauthors, 2019: Spatial variability of winds and HRRR-NCEP model error statistics at three Doppler-lidar sites in the wind-energy generation region of the Columbia River Basin. J. Appl. Meteor. Climatol., 58, 1633-1656, https://doi.org/10.1175/JAMC-D-18-0244.1.

Pielke, R. A., 1984: Mesoscale Meteorological Modeling. Academic Press, $612 \mathrm{pp}$.

Post, M. J., and R. E. Cupp, 1990: Optimizing a pulsed Doppler lidar. Appl. Opt., 29, 4145-4158, https://doi.org/10.1364/ AO.29.004145.

Reible, D. D., J. E. Simpson, and P. F. Linden, 1993: The sea breeze and gravity-current frontogenesis. Quart. J. Roy. Meteor. Soc., 119, 1-16, https://doi.org/10.1002/qj.49711950902.

Schroeder, M. J., M. A. Fosberg, O. P. Cramer, and C. A. O'Dell, 1967: Marine air invasion of the Pacific Coast: A problem analysis. Bull. Amer. Meteor. Soc., 48, 802-808, https://doi.org/ 10.1175/1520-0477-48.11.802.

Seaman, N., 2000: Meteorological modeling for air-quality assessments. Atmos. Environ., 34, 2231-2259, https://doi.org/10.1016/ S1352-2310(99)00466-5.

Sharp, J., and C. F. Mass, 2002: Columbia Gorge gap flow: Insights from observational analysis and ultra-high-resolution simulation. Bull. Amer. Meteor. Soc., 83, 1757-1762, https://doi.org/ 10.1175/BAMS-83-12-1757.

- and — 2004: Columbia Gorge gap winds: Their climatological influence and synoptic evolution. Wea. Forecasting, 19, 970-992, https://doi.org/10.1175/826.1.

Shaw, W. J., and Coauthors, 2019: The Second Wind Forecast Improvement Project (WFIP 2): General overview. Bull. Amer. Meteor. Soc., 100, 1687-1699, https://doi.org/10.1175/BAMS-D18-0036.1.

Simpson, J. E., 1994: Sea Breeze and Local Winds. Cambridge University Press, $234 \mathrm{pp}$.

Skamarock, W. C., 2004: Evaluating mesoscale NWP models using kinetic energy spectra. Mon. Wea. Rev., 132, 3019-3032, https://doi.org/10.1175/MWR2830.1.

Smith, E. N., J. G. Gebauer, P. M. Klein, E. Fedorovich, and J. A. Gibbs, 2019: The Great Plains low-level jet during PECAN: Observed and simulated characteristics. Mon. Wea. Rev., 147, 1845-1869, https://doi.org/10.1175/MWR-D18-0293.1.
Staley, D. O., 1957: The low-level sea breeze of northwest Washington. J. Meteor., 14, 458-470, https://doi.org/10.1175/ 1520-0469(1957)014<0458:TLLSBO > 2.0.CO;2.

_ 1959: Some observations of surface-wind oscillations in a heated basin. J. Meteor., 16, 364-370, https://doi.org/10.1175/ 1520-0469(1959)016<0364:SOOSWO >2.0.CO;2.

Sun, J., and Coauthors, 2002: Intermittent turbulence associated with a density current passage in the stable boundary layer. Bound.-Layer Meteor., 105, 199-219, https://doi.org/10.1023/ A:1019969131774.

Toms, B. A., J. M. Tomaszewski, D. D. Turner, and S. E. Koch, 2017: Analysis of a lower-tropospheric gravity wave train using direct and remote sensing measurement systems. Mon. Wea. Rev., 145, 2791-2812, https://doi.org/10.1175/MWR-D-16-0216.1.

Turner, D. D., and W. G. Blumberg, 2019: Improvements to the AERIoe thermodynamic profile retrieval algorithm. IEEE J. Sel. Top. Appl. Earth Obs. Remote Sens., 12, 1339-1354, https://doi.org/10.1109/JSTARS.2018.2874968.

Wang, M., and P. Ullrich, 2018: Marine air penetration in California's Central Valley: Meteorological drivers and the impact of climate change. J. Appl. Meteor. Climatol., 57, 137154, https://doi.org/10.1175/JAMC-D-17-0089.1.

Whiteman, C. D., S. Zhong, W. J. Shaw, J. M. Hubbe, and X. Bian, 2001: Cold pools in the Columbia Basin. Wea. Forecasting, 16, 432-447, https://doi.org/10.1175/1520-0434(2001)016<0432: CPITCB $>2.0 . \mathrm{CO} ; 2$.

Wilczak, J. M., and Coauthors, 2015: The Wind Forecast Improvement Project (WFIP): A public-private partnership addressing wind energy forecast needs. Bull. Amer. Meteor. Soc., 96, 1699-1718, https://doi.org/10.1175/BAMS-D-14-00107.1.

- - , and Coauthors, 2019: The Second Wind Forecast Improvement Project (WFIP2): Observational field campaign. Bull. Amer. Meteor. Soc., 100, 1701-1723, https://doi.org/ 10.1175/BAMS-D-18-0035.1.

Zaremba, L. L., and J. J. Carroll, 1999: Summer wind flow regimes over the Sacramento Valley. J. Appl. Meteor., 38, 1463-1473, https://doi.org/10.1175/1520-0450(1999)038<1463:SWFROT> 2.0.CO;2.

Zhong, S., J. Li, C. B. Clements, S. F. J. De Wekker, and X. Bian, 2008: Forcing mechanisms for Washoe Zephyr-A daytime downslope wind system in the lee of the Sierra Nevada. J. Appl. Meteor. Climatol., 47, 339-350, https://doi.org/10.1175/ 2007JAMC1576.1. 